\title{
Fatiga, límites de deuda y espacio fiscal de los gobiernos estatales en México
}

\author{
Fiscal Fatigue, Debt limits and Fiscal Space of Mexican State Governments
}

Ignacio Ruelas Ávila y Alain Dimitrius Izquierdo Reyes*

\begin{abstract}
Resumen: Este artículo ofrece un análisis del espacio fiscal de los gobiernos estatales mexicanos: evalúa los efectos de la descentralización en las cuentas públicas subnacionales y sustenta recomendaciones de sostenibilidad fiscal para las entidades federativas. Se define espacio fiscal como una medida de disponibilidad de recursos que permite ajustar la política fiscal por la vía del financiamiento o del gasto público. Mediante la operacionalización de tres variables, balance primario, fatiga fiscal y límites de deuda, se estudia el espacio fiscal con el que las entidades federativas han hecho frente a sus responsabilidades económicas durante el periodo 2003-2018. Los resultados demuestran dos situaciones: la primera es que el espacio fiscal de los gobiernos estatales mexicanos es reducido o incluso requerido, es decir, los datos evidencian estrechez en términos de los balances primarios, y la segunda es que, al mismo tiempo, las entidades federativas aún tienen margen para el acceso a obligaciones de deuda.

Palabras clave: gobierno estatal, presupuesto estatal, déficit de presupuesto estatal, deuda estatal, gestión de la deuda.
\end{abstract}

*Ignacio Ruelas Ávila es asistente de investigación en el Centro de Investigación y Docencia Económicas (CIDE, Región Centro), consultor en la Comisión Económica para América Latina y el Caribe (Cepal) y docente en la Universidad de la Ciudad de Aguascalientes (UCAGs). Circuito Tecnopolo Norte 117, colonia Tecnopolo Pocitos II, 20313, Aguascalientes, Ags., México. Tel. 449290 9356. Correo-e: ignacio.ruelas@ cide.edu. ORCID: https://orcid.org/0000-0003-2156-2427. Alain Dimitrius Izquierdo Reyes es jefe de Servicios de Finanzas en la representación del Instituto Mexicano del Seguro Social (IMSs), en Jalisco, e imparte clases de Economía y Finanzas Públicas en posgrados y licenciaturas. Actualmente es candidato a doctor en Estudios Fiscales por la Universidad de Guadalajara (UDG). Universidad Panamerciana, Calz. Nueva 49, Granja, 45010, Zapopan, Jal., México. Tel. 331439 2092. Correo-e: aizquierdo@up.edu.mx. orcid: https://orcid.org/0000-0002-3758-1481. Los autores deseamos agradecer a los expertos anónimos que dictaminaron el artículo y a quienes nos dieron comentarios previos, específicamente a Itzamá Enríquez Iñiguez, Juan Pablo Jiménez, Giorgio Brosio y Jorge de Anda Salazar..

Artículo recibido el 20 de diciembre de 2019 y aceptado para su publicación el 1 de diciembre de 2020 .

DOI: http://dx.doi.org/10.29265/gypp.v30i2.878 
Abstract: In this paper, we explore the fiscal space of Mexican state governments: it evaluates the effects of decentralization on subnational public accounts and supports recommendations for fiscal sustainability for the states. Fiscal space is defined as a measure of the availability of resources that allows the adjustment of fiscal policy through financing or public spending. Through the operationalization of three variables, like primary balance, fiscal fatigue and debt limits, the fiscal space with which the states have faced their economic responsibilities during the 2003-2018 period is analyzed. The results show two situations: the first is that the fiscal space of the Mexican state governments is reduced or even required, that is, the data show narrowness in terms of the primary balance sheets, and the second is that, at the same time, these governments still have room for access to debt obligations.

Keywords: state government, state budget, state budget deficit, state debt, debt management.

\section{INTRODUCCIÓN}

- $\mathrm{n}$ México, durante las últimas décadas, los gobiernos subnacionales han mostrado una mayor participación en el diseño y ejecución de los planes fiscales. Esta tendencia comenzó con la descentralización, ocurrida en los años noventa, de un sector importante de servicios sociales básicos como la educación y la salud. Desde entonces, han acaecido una serie de cambios, en el sistema fiscal mexicano, que han alterado las cuentas públicas de los gobiernos estatales. En lo que respecta a la ejecución del gasto, las entidades federativas han adquirido más responsabilidades; mientras que, en lo concerniente al financiamiento, han evidenciado debilidades en el esfuerzo fiscal, reveladas en los bajos niveles de recaudación tributaria.

En el transcurso de este proceso y sus consecuencias, dos instrumentos de política pública han sido importantes para reducir las brechas emergentes e impulsar las economías regionales: las transferencias intergubernamentales —a través de las participaciones y las aportaciones federales - y el endeudamiento. Las transferencias han ganado una importancia determinante dentro del espacio fiscal de los gobiernos; mientras que el endeudamiento lo ha hecho a una menor velocidad y en valores acumulados que, vistos de manera agregada, no permiten anticipar algún riesgo macroeconómico (Jiménez y Ruelas, 2016). No obstante, se han dado casos de gobiernos estatales que han alcanzado altos niveles de endeudamiento, y han tensionado, así, la sostenibilidad de sus finanzas públicas.

Es así que discutir la situación del espacio fiscal de los gobiernos estatales resulta urgente en un entorno en el que los gobiernos han sumado significativas responsabilidades de gasto durante las últimas décadas; a la par que han intensificado su dependencia de las transferencias del gobierno federal, y gradualmente han hecho del endeudamiento su segunda fuente para financiar el gasto público. 
Es urgente, también, porque la estrechez en las finanzas públicas le impide al Estado ofrecer una respuesta oportuna a las demandas de la ciudadanía, así como distribuir los recursos fiscales necesarios para acelerar un crecimiento sostenible a nivel subnacional, y ello tiene por consecuencia una disminución del rol de los gobiernos estatales en el desarrollo del país.

Ahora bien, aunque existen investigaciones recientes que estiman el espacio fiscal para países desarrollados y en desarrollo —incluyendo entre estos últimos el caso de México-1 (Baum et al., 2017; FMI, 2018; Ganiko et al., 2016; Ghosh et al., 2011; Lozano-Espitia y Julio-Román, 2019; Ostry et al., 2010), hay pocos estudios que exploran empíricamente este concepto en el ámbito subnacional; entre ellos destaca lo realizado por Bastos y Pineda $(2013),{ }^{2}$ para el caso de los estados brasileños.

Ante esta carencia en la investigación académica, este trabajo contribuye con un análisis del espacio fiscal de los gobiernos subnacionales mexicanos. Su motivación se sustenta en las presiones de gasto público que han acumulado los gobiernos estatales y en la débil capacidad de estos para generar los ingresos necesarios que les permitan solventarlas. De tal manera que la investigación estudia la evolución del espacio fiscal de los gobiernos subnacionales con el propósito de identificar, de manera anticipada, aquellos niveles de deuda que pueden desencadenar problemas de sostenibilidad en un futuro.

En lo que respecta a la metodología, el objeto de análisis es el espacio fiscal de los gobiernos estatales. Este se estima a través de diveresos datos fiscales y económicos de las entidades federativas para el periodo 2003-2018. Y, para efectos de su cálculo, se entiende como una medida que evidencia las posibilidades de los gobiernos para aumentar el gasto público en distintos rubros (sociales y económicos) sin alterar su posición financiera inicial (Heller, 2005).

Los resultados arrojan dos datos de interés. Por una parte, muestran que los gobiernos estatales cuentan con un espacio fiscal reducido, e incluso requerido, en términos del balance primario de los gobiernos estatales. Y, por otra parte, evidencian que los gobiernos aún tienen espacio fiscal disponible, en términos de acceso a créditos. En general, se complementa lo discutido en la literatura previa, respec-

${ }^{1}$ Para el caso de México, el estudio del Fondo Monetario Internacional (2018) señala que existe espacio fiscal limitado y, por ende, sugiere que este no se utilice para impulsar el crecimiento. En su lugar, recomienda bajar los niveles de deuda en relación con el PIB, y así crear espacio para atender las necesidades sociales y de infraestructura en el medio plazo.

${ }^{2}$ En este estudio, los autores encuentran que los estados brasileños cuentan con espacio fiscal; no obstante, remarcan las disparidades que efectivamente existen entre estos. 
to a la estrechez que enfrentan los gobiernos subnacionales en el ámbito de la descentralización fiscal (por el lado de las responsabilidades de gasto e ingresos) en países en desarrollo, y se respalda la evidencia existente sobre la fatiga y los límites de deuda en gobiernos subnacionales en sistemas descentralizados.

El documento está organizado en cuatro secciones. La primera corresponde a una revisión de literatura, en la que se analizan distintos acercamientos teóricos a la noción de espacio fiscal desde el enfoque de la descentralización. En la segunda sección se desarrolla el modelo teórico que se pretende sustentar empíricamente y se explica la estrategia metodológica para calcular el espacio fiscal. Luego, en la tercera, se discuten los resultados obtenidos. Finalmente, en la cuarta sección, se exponen algunas conclusiones y recomendaciones de política pública orientadas a procurar la sostenibilidad fiscal de los estados.

\section{REVISIÓN DE LITERATURA}

\section{La descentralización fiscal: asignación de responsabilidades y espacio fiscal}

La capacidad de respuesta de un gobierno se mide a través de la provisión de bienes y servicios que brinda a la sociedad. A su vez, esta capacidad depende de los recursos de los cuales dispone el gobierno para cumplir las necesidades sociales y económicas demandadas por la población. En este sentido, las finanzas públicas son un instrumento esencial en relación con los esquemas de financiamiento y las prioridades de gasto declaradas tanto en los programas como en las políticas definidas en los presupuestos públicos. Por ello, es fundamental conocer, con mayor profundidad, los factores o determinantes que permiten expandir la frontera de los recursos públicos, entre ellos, el espacio fiscal.

Sobre el espacio fiscal, Heller (2005) advierte que su uso en el ámbito de las políticas públicas pocas veces viene acompañado de una definición clara y operacionalizable. Este autor propone — en su versión más amplia — entender este concepto como la disponibilidad financiera con la que cuentan los gobiernos para aumentar el gasto público (en distintas prioridades de política pública) o recortar impuestos, sin alterar su sostenibilidad.

Entonces, considerando la aportación de Heller, y teniendo en cuenta las características administrativas de México, si se pretende estudiar el espacio fiscal subnacional de este país, es pertinente analizar la disponibilidad financiera como una variable dependiente del grado de descentralización. Por ello, en lo siguiente, se revisan las aportaciones teóricas y prácticas en torno a la descentralización y su impacto en el ámbito subnacional. Luego, con base en un posicionamiento respecto a tal estado del arte, se conceptualiza la noción de espacio fiscal. 
Para dimensionar el espacio fiscal en el marco de la descentralización de responsabilidades de gasto e ingreso, es importante responder, antes que nada, "quién hace qué" en las relaciones fiscales intra e intergubernamentales. Musgrave (1959) sostiene que las funciones del sector público son tres: estabilización, asignación y distribución. La estabilización, cuyo cometido es mantener el pleno empleo y los precios estables, recae en instituciones centralizadas (gobierno central y banco central). Mientras que la asignación de recursos, a través de bienes y servicios, por medio de impuestos y subvenciones, es responsabilidad de todos los ámbitos de gobierno. Por último, la distribución, que se encarga de la forma en que los bienes producidos se reparten en la sociedad, es un rol que corresponde solamente al gobierno central. Se advierte así que, de las tres funciones, la asignación es la única que implica al ámbito subnacional. Por ende, es esta la que afecta el espacio fiscal de los estados.

Efectivamente, en una modalidad descentralizada, la asignación de recursos - es decir, el alcance del financiamiento y el grado de autonomía presupuestaria-influye en la fortaleza recaudatoria de los entes públicos subnacionales. En otras palabras, la descentralización fiscal no es inocua; de acuerdo con Tiebout (1956), Tirole (1994) y Breton (1998), su comportamiento es semejante al de un mercado competitivo. Según estos autores, las entidades subnacionales que comparten zonas metropolitanas interactúan en un espacio en donde cada una tiene que diferenciarse en la oferta de bienes públicos con la finalidad de ajustarse a las demandas locales para atraer más residentes a su territorio.

En la misma línea, Brennan y Buchanan (1980) argumentan que la competitividad se fortalece cuando existe pluralidad electoral. En la presencia de esta —afirman — se vigila de mejor manera la asignación de los recursos públicos, en especial en materia hacendaria, dado que los grupos antagónicos demandan mayor rendición de cuentas al Estado. Esto se traduce, a su vez, en más eficiencia y eficacia, lo cual permite a cada entidad federativa aumentar sus recursos fiscales en el largo plazo. Asimismo, Tiebout (1956) destaca que la ciudadanía tiene la opción de seleccionar el lugar de residencia que mejor se adapte a sus preferencias y pago de impuestos dentro de su territorio ("voto con los pies").

Oates (1972), por su parte, sugiere que, en ausencia de los ahorros correspondientes a los costos de la provisión centralizada de bienes públicos locales y de externalidades interjurisdiccionales, la descentralización del gobierno puede proporcionar niveles de consumo eficientes — en el sentido de Pareto- en cada jurisdicción (en lugar de mantener un nivel uniforme de consumo en todas). Sobre esto último, Bahl y Linn (1992) señalan que la descentralización permite 
elevar el bienestar de la ciudadanía conforme mejora la eficiencia en la provisión de bienes y servicios públicos.

Olson (1969) ofrece otra perspectiva relevante en esta materia, mediante el principio de equivalencia fiscal; concepto que incorpora el tamańo de la jurisdicción en la provisión de los servicios y el área geográfica que recibe los beneficios del proceso. Lo que propone, en términos breves, es que el pago de impuestos en una jurisdicción debe corresponder a los beneficios recibidos en esta. Este principio es relevante cuando existen disparidades en el tamaño de los territorios; centrándose en el tamaño óptimo de la jurisdicción y sus implicaciones (Buchanan, 1965; Rothenberg, 1970; Tiebout, 1956; Tullock, 1969) para explicar el comportamiento de las personas al elegir jurisdicciones y su relación con la provisión de bienes y servicios públicos.

En contraste con las posturas previas, que se inclinan por la descentralización fiscal, hay otra literatura (Prud'homme, 1995; Terman y Feiock, 2015; Weingast, 1995, 2008; Willis et al., 1999) que identifica un conjunto de ineficiencias que pueden mermar el desarrollo efectivo de los procesos de descentralización.

En Weingast (2008), por ejemplo, es posible identificar puntualmente estas ineficiencias. Primero, la falta de una autoridad política subnacional puede inhibir el proceso competitivo entre jurisdicciones y, con ello, la capacidad de los gobiernos locales para adaptar las políticas a sus contextos. Segundo, la ausencia de un mercado común entre jurisdicciones aumenta la posibilidad de que los gobiernos locales caigan en actos de corrupción, búsqueda de rentas (rent seeking) y asignación ineficiente de los recursos. Tercero, los gobiernos locales suelen ser más propensos a tener restricciones presupuestarias blandas, lo que produce gastos y endeudamientos que rebasan las posibilidades y capacidades de estos gobiernos. Y, cuarto, la ausencia de una institucionalidad local sólida da pie para que el gobierno central mantenga la amenaza constante a las jurisdicciones subnacionales que buscan la independencia política.

En la práctica, la evidencia respalda las observaciones de los antagonistas de la descentralización. En los países emergentes o en vías de desarrollo, algunas experiencias relevantes en procesos de descentralización y federalismo fiscal, vistas desde la perspectiva de la economía política, muestran que las instituciones formales e informales, así como las reglas y los actores, influyen en el desempeño del proceso fiscal diseñado y de sus resultados (Willis et al., 1999; Weingast, 1995; Terman y Feiock, 2015). Específicamente, Prud'homme (1995) ha encontrado que en países en vías de desarrollo la descentralización fiscal, en ocasiones, deriva en problemas como la corrupción y la incapacidad técnica de 
la burocracia local; ambas, debilidades que afectan negativamente las preferencias locales.

Como respuesta a estas observaciones, Oates (2008) señala que el federalismo y su evolución deben introducir conceptos en los que se asuma el comportamiento de los agentes que interactúan en las instituciones. Advierte que los aspectos de economía política — como los recién mencionados- algunas veces generan un impacto distinto al del diseño; por lo tanto, se vuelve importante revisar la estructura de los incentivos de acuerdo con las reglas blandas o rígidas de las instituciones formales e informales de los países. Asimismo, autores como León-Alfonso (2006) y Bossuyt (2013) profundizan en estos aspectos, y destacan la importancia de las responsabilidades y atribuciones de cada nivel de gobierno, la configuración electoral —en la cual la ciudadanía y los partidos participan maximizando sus decisiones-y la cooperación estratégica entre los sectores social, privado y público.

En suma, la literatura revisada muestra que los promotores de la descentralización fiscal consideran que esta favorece la competitividad y, en consecuencia, mejora la calidad de vida de la población. En contraste, otros autores señalan que la descentralización conlleva ineficiencias que pueden perjudicar las preferencias y tornar ineficiente la coordinación entre los gobiernos subnacionales.

En lo que concierne al espacio fiscal, con base en las posturas a favor de la descentralización, es posible afirmar que este se amplía. Sin embargo, al considerar las observaciones empíricas de las posturas que la cuestionan, lo indicado es afirmar que se reduce, sobre todo, en los países en vías de desarrollo. Dicho de otra manera, por un lado, el espacio fiscal puede aumentarse, gracias a la eficiente asignación de recursos - materializada en un financiamiento óptimo- a las entidades federativas para que estas ejerzan los gastos necesarios para satisfacer las necesidades de la población y, por otro lado, las diversas experiencias advierten la posibilidad de restricciones presupuestarias blandas (excesivos gastos y endeudamientos) y actos de corrupción, en estos gobiernos, que reducen el espacio fiscal y, con ello, la sostenibilidad de sus cuentas públicas.

Por lo tanto, al considerar ambas posturas, para este trabajo, se propone usar el espacio fiscal como un concepto integral y medible que evalúe los efectos de la descentralización en las cuentas públicas subnacionales.

\section{La descentralización y el espacio fiscal en México}

De acuerdo con Heller, para analizar el espacio fiscal, conviene discutir algunas implicaciones relevantes de la sostenibilidad financiera, como la capacidad para generar ingresos fiscales en el corto y medio plazo, las prioridades de gasto públi- 
co y la disponibilidad de ingresos fiscales provenientes de fuentes externas de financiamiento.

En el ámbito estatal mexicano, esta propuesta de análisis adquiere sentido si se enfatizan tres problemas que se han estudiado en trabajos recientes: la baja capacidad para generar ingresos tributarios propios, los desbalances verticales y horizontales — reflejados principalmente por las responsabilidades de gasto adquiridas por los gobiernos estatales - y la dependencia de los gobiernos respecto de las transferencias intergubernamentales.

\section{Débil esfuerzo fiscal}

El instrumento más importante con el que cuentan los gobiernos para crear espacio fiscal es, sin duda, la recaudación de impuestos. A nivel subnacional, esta medida toma mayor importancia dadas las profundas debilidades que países como México han mostrado en cuanto a la carga tributaria lograda en los gobiernos estatales.

En este sentido, la gráfica 1 muestra los pobres niveles de recaudación de impuestos de los gobiernos subnacionales en México. En relación con el porcentaje del PIB, los ingresos tributarios se ubican por debajo de 1 por ciento, cifra

GRÁFICA 1. Recaudación de ingresos tributarios, 2018 (porcentaje del PIB)

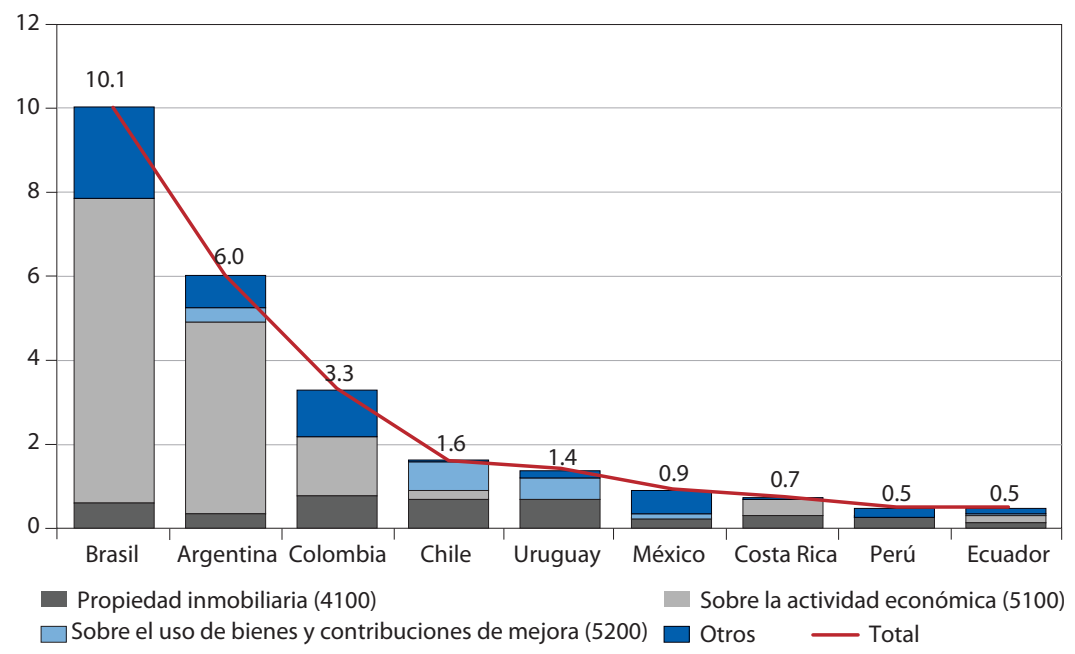

Fuente: Elaboración propia con base en cifras tomadas de OCDE et al. (2020). 
que es considerablemente inferior a lo logrado en Brasil (10.1\%), Argentina (6\%), Colombia (3.3\%), Chile (1.6\%) y Uruguay (1.4\%).

Sumado a estos niveles, existe un cúmulo importante de evidencia que, para el caso de México, muestra los determinantes y las ineficiencias de los gobiernos estatales y municipales en los procesos de recaudación de impuestos. Resaltan las incompetencias relacionadas con las capacidades institucionales, administrativas y de gestión (Cabrero, 2004; Espinosa et al., 2018; ${ }^{3}$ Ruelas, 2015), la dificultad de aprovechar las potestades tributarias disponibles (Gómez y Jiménez, 2017) y la dependencia de las transferencias intergubernamentales (Bonet y Rueda, 2012; Broid, 2010; Chávez, 2014; Guillermo y Vargas, 2017; Sepúlveda y MartinezVazquez, 2012; Valenzuela-Reynaga e Hinojosa-Cruz, 2017). Además, resulta determinante el contexto económico local y nacional (Broid, 2010; Chávez, 2014; Sepúlveda y Martinez-Vasquez, 2012) y la concentración del ingreso y los altos niveles de marginación (Aguilar, 2010; Bonet y Rueda, 2012; Broid, 2010; Chávez, 2014; Ibarra, 2013; Gámez e Ibarra-Yáñez, 2009; Ramírez y Erquizio, 2011; Sour, 2008).

Esta debilidad del esfuerzo fiscal se identifica analizando la estructura de los ingresos totales de las entidades federativas en términos agregados. Como se muestra en el cuadro 1, los ingresos estatales ascienden a 8.5 por ciento del PIB; cifra que, en términos desagregados, se compone de 87.2 por ciento de ingresos provenientes de transferencias (participaciones y aportaciones federales), y apenas 4.8 por ciento de recaudación de impuestos.

Del total de los ingresos tributarios, más de 71 por ciento se origina en la recaudación del impuesto a la nómina; siguiendo en orden de importancia los ingresos del impuesto sobre la tenencia o uso de vehículo, cuya participación porcentual es de 12 por ciento del total de los ingresos tributarios estatales.

Respecto al impuesto a la nómina, se suele destacar, como ventaja, lo fácil que resulta su administración, sobre todo si se aplica a empresas grandes y cuando la economía tiene un alto grado de formalización laboral; sin embargo, su principal desventaja es que puede ser una barrera para la generación de empleo en el sector formal, y terminar siendo una forma encubierta de exportar impuestos a otras

${ }^{3}$ En Espinosa et al. (2018), si bien se encuentra que las transferencias pueden tener un efecto positivo en el esfuerzo recaudatorio del impuesto predial, el estudio se centra en las tareas administrativas como la valuación catastral y el uso de tecnologías adecuadas que ayuden a mantener la información actualizada. Los autores sugieren que estas tareas pueden ser determinantes en el rezago recaudatorio de entidades federativas en donde la coordinación intergubernamental resulte más compleja; producto, por ejemplo, de un alto número de municipios que conforman la entidad. 
CUADRO 1. Estructura de los ingresos totales de los gobiernos estatales, 2018, como porcentaje del PIB y como porcentaje de los ingresos totales

\begin{tabular}{lcc}
\hline Ingresos estatales & $\begin{array}{c}\text { Monto como porcentaje } \\
\text { del PIB }\end{array}$ & $\begin{array}{c}\text { Participación relativa, } \\
\text { en porcentaje del total } \\
\text { de ingresos }\end{array}$ \\
\hline Impuestos & 0.4 & 4.8 \\
Cuotas y aportaciones de seguridad social & 0.1 & 1.0 \\
Derechos & 0.2 & 2.7 \\
Productos & 0.0 & 0.5 \\
Aprovechamientos & 0.1 & 1.5 \\
Participaciones federales & 3.2 & 37.6 \\
Aportaciones federales & 4.2 & 49.6 \\
Otros ingresos & 0.2 & 2.3 \\
Contribuciones de mejoras & 0.0 & 0.1 \\
Total & 8.5 & 100 \\
\hline
\end{tabular}

Fuente: Elaboración propia con base en datos del INEGI (2019 y 2020). Nota: El cálculo de los ingresos como porcentaje del PIB se hizo a valores corrientes.

GRÁFICA 2. Distribución de los ingresos tributarios estatales, 2018, como porcentaje del total

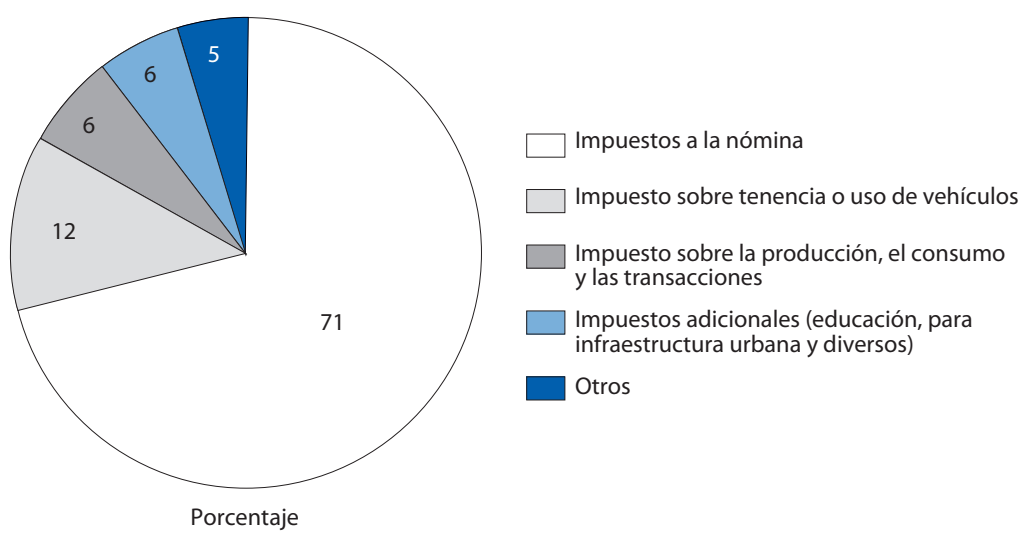

Fuente: Elaboración propia con base en datos del INEGI (2020). 
jurisdicciones, al gravar en virtud del principio del origen en el supuesto de que este afecte los costos de producción (Larios et al., 2004; Gómez y Jiménez, 2017). En lo que se refiere al impuesto sobre la tenencia de vehículos, es válido destacar que, desde 2012, dejó de ser un impuesto federal cuya distribución se realizaba vía participaciones, quedando asignada su administración a las entidades federativas. En efecto, algunos gobiernos estatales han dejado de cobrar este impuesto (con tasa cero o derechamente derogándolo), disminuyendo así su recaudación (Meléndez, 2019), y afectando negativamente fuentes potenciales de ingresos propios estatales.

\section{Desbalances verticales y horizontales}

Con el avance de los procesos de descentralización y distribución de funciones, la eficiencia planteada por lo promotores de la descentralización (Oates, 1972; Tiebout, 1961) ha sido cuestionada debido a la asimetría potencial entre las responsabilidades de gasto descentralizadas y la capacidad con la que los subsectores institucionales, distintos al gobierno central, cuentan para financiarlas. De acuerdo con Sepúlveda y Martinez-Vazquez (2012), la magnitud de estas disparidades fiscales, tanto entre distintos niveles de gobierno como entre los del mismo nivel, crean lo que se conoce como desequilibrios verticales y horizontales, respectivamente.

Por un lado, el desequilibrio vertical surge con la descentralización de las responsabilidades de gasto y transferencia de recursos hacia los niveles intermedios y locales de gobierno, ya que los gobiernos subnacionales pierden los incentivos recaudatorios, la transferencia de capacidades y las potestades legales suficientes para la generación de ingresos propios. El desequlibirio horizontal, por otro lado, se evidencia en las grandes diferencias que existen en las capacidades fiscales entre los gobiernos de un mismo nivel, ya sean de orden local o intermedio, debido a que se acrecientan las desigualdades territoriales. Por mencionar un ejemplo: la capacidad institucional y económia del gobierno de Chiapas (estado con desventajas sociales y económicas) no es igual a la capacidad del gobierno de Nuevo León (estado rico, con alto potencial productivo).

En América Latina, las responsabilidades de gasto que se han descentralizado no han sido complementadas con capacidades administrativas y legales para generar ingresos propios (Brosio y Jiménez, 2012; Jiménez y Ruelas, 2016, 2018; oCDE et al., 2020). En México, algunas de las áreas en donde se han expresado este tipo de disparidades son las de educación, salud y seguridad pública. Según un conjunto importante de trabajos, la distribución de responsabilidades de gasto 
hacia estos sectores no ha sido acompañada de una distribución de recursos suficientes, ha generado problemas financieros en los erarios de los gobiernos estatales, ha perpetuado las inequidades en la asignación de los fondos de financiamiento y tiende a evidenciar que los esfuerzos para asignar recursos a estas funciones de gobierno han sido débiles y dispares ${ }^{4}$ al mismo tiempo que el gasto se ha inclinado a ser mayor en las entidades federativas más ricas ${ }^{5}$ (Cárdenas, 2013; Cárdenas y Luna, 2007; González, 2005; Ornelas, 2018; Sobarzo, 2004; Soria, 2018; Trujillo, 2013).

Con el propósito de atenuar estas disparidades, el sistema de transferencias intergubernamentales en México se conforma por las participaciones federales, integradas en el Ramo 28, y las aportaciones federales, contenidas en el Ramo 33. El Ramo 28 tiene un carácter resarcitorio, ya que establece criterios de asignación de los recursos de manera proporcional a la participación de las entidades federativas en la actividad económica y la recaudación; por lo tanto, pretende generar incentivos para incrementar el crecimiento económico y el esfuerzo recaudatorio de las entidades. De tal manera que las participaciones federales son parte del gasto no programable dentro del presupuesto de egresos de la federación, debido a que su monto responde a una estimación de lo que se espera transferir a los estados y municipios, dependiendo de la recaudación de los ingresos federables que son participables. Además, son un recurso no etiquetado, es decir, no tienen un destino específico en el gasto de las entidades federativas y municipios; se ejercen de manera autónoma por parte de los gobiernos locales (CEFP, 2017).

En cuanto al Ramo 33, las transferencias tienen un carácter compensatorio. $\mathrm{Su}$ finalidad consiste en asignar recursos en proporción directa a los rezagos y necesidades que observan las entidades federativas en materia de salud, educación, infraestructura y desarrollo social, entre otros. Las transferencias son parte del gasto programable, por lo que su monto queda asignado en el presupuesto de egresos de la federación, garantizando con ello a las entidades la recepción de ese monto con independencia de su desempeño económico y recaudatorio. Es decir, son recursos etiquetados, con destino específico en las estructuras de gasto de las

\footnotetext{
${ }^{4}$ En el sector educativo, con el "Acuerdo para la modernización de la educación básica", de 1992, se descentralizaron funciones importantes, entre las cuales destaca la administración de casi 70 por ciento de la matrícula de ese nivel educativo (Ornelas, 2018: 176).

${ }^{5} \mathrm{Al}$ respecto, Soria (2018) demuestra que el costo de la inseguridad y la delincuencia para 2013 fue de 5.69 por ciento del PIB y la media per cápita de 6799 pesos, con un gasto mayor en las entidades federativas más ricas.
} 
entidades federativas, y son estas quienes deben ejercerlo de acuerdo con las leyes y normativas aplicables (CEFP, 2017).

Al respecto, Ángeles et al. (2019) sugieren que el efecto positivo del gasto descentralizado por conducto del Ramo 33, en el crecimiento y la distribución del ingreso entre entidades, aunque no sea suficiente para revertir las divergencias, es consistente con la teoría del federalismo fiscal, particularmente, con los argumentos que apoyan la descentralización. Sin embargo — agregan - la evidencia de la desigualdad entre estados no sostiene la teoría en términos de distribución equitativa del ingreso y la asignación efectiva de los recursos. Esta evidencia va en el sentido de lo encontrado por Sovilla et al. (2018), autores que analizan el caso de Chiapas, y sugieren que la descentralización de recursos fiscales en esta entidad ha apuntado hacia la redistribución territorial de tales recursos, pero no ha logrado repercutir de manera positiva en los indicadores económicos estatales. Al respecto, la principal explicación de los autores reside en la ineficiencia de la gestión de los recursos transferidos por la federación, es decir, la presencia de una restricción presupuestaria blanda en el manejo de estos recursos públicos.

\section{La dependencia respecto de las transferencias}

Aunado a los límites de la autonomía fiscal subnacional, países como México han demostrado poca capacidad para generar ingresos fiscales cuyo peso relativo sea superior a lo recibido por la vía de las transferencias intergubernamentales. En montos agregados, el peso de las transferencias intergubernamentales, para el caso de México, es cercano a 9 por ciento del producto interno bruto, cifra equivalente a más de 86 por ciento de los ingresos totales de los gobiernos estatales y municipales de este país (oCDE et al., 2020); mientras que la parte de ingresos propios mantiene una participación relativa menor, como muestra la gráfica 3.

Los datos de la gráfica respaldan que, en la práctica, este sistema produce una fuerte dependencia de las autoridades subnacionales hacia las transferencias federales. Esta descentralización está focalizada únicamente en el gasto, lo que deriva, como plantea Cabrero (2013), en una "mera descentralización ficticia", en tanto que limita las acciones de los gobiernos subnacionales y actúa como un mecanismo regulador que controla la autonomía de los estados y municipios. Tal distorsión de los ingresos, en México, crea desequilibrios verticales que constituyen, en palabras del mismo Cabrero, "la trampa del federalismo fiscal". Estos desequilibrios no generan los incentivos adecuados, lo que significa que obstaculizan el cumplimiento del precepto que indica que cada nivel gubernamental debe generar los ingresos que gasta. 
GRÁFICA 3. Estructura de ingresos fiscales por habitante, de los gobiernos estatales, $2018(2003=100)$

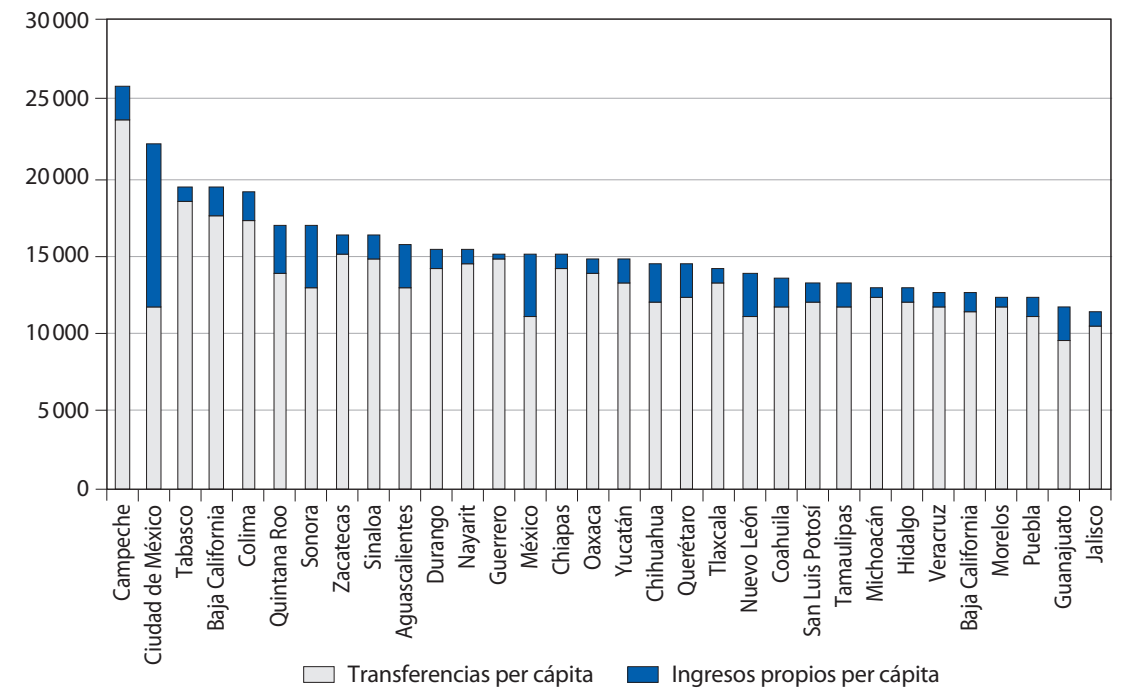

Fuente: Elaboración propia con base en datos del INEGI (2020).

\section{MODELO TEÓRICO, ESTRATEGIA METODOLÓGICA Y BASES DE DATOS}

\section{Espacio fiscal en los balances primarios}

Para este trabajo, en primera instancia, se recurre a una definición del espacio fiscal que permita ser operacionalizada con los datos disponibles. De tal manera que sea posible explorar la evolución de las finanzas públicas de los gobiernos estatales mexicanos; considerando, para ello, además de los ingresos y gastos públicos, la posición crediticia y el crecimiento económico estatal (PIBE).

Esta primera definición, de naturaleza cuantitativa, se refiere a la disponibilidad de recursos fiscales para lograr objetivos socieconómicos específicos. Este haber, señalado teóricamente, no debería alterar la sostenibilidad de la posición financiera del gobierno o de la economía estatal en su conjunto. Para aproximarse a esta medida se calcula el espacio fiscal a través de la siguiente ecuación:

$$
b p_{i t} *=\left(\frac{r_{i t}-g_{i t}}{1+g_{i t}}\right) * d_{i t-1}
$$


Para ello, es necesario considerar que el balance primario es la diferencia entre ingresos y gastos públicos netos del pago de intereses de la deuda pública:

$$
b p_{i t}=i_{i t}-\left(g_{i t}-i n_{i t}\right)
$$

En este marco analítico, el balance primario que se requiere para lograr una posición financiera sostenible $\left(b p_{i t} *\right)$ depende de la tasa de interés real en la entidad $i$ en el periodo $t\left(r_{i t}\right)$, de la tasa de crecimiento de la economía $i$ de la entidad, en un periodo determinado $t\left(g_{i t}\right)$, y del saldo de la deuda del periodo anterior de la entidad $i$ en el año anterior $t-1\left(d_{i t-1}\right)$. Si la tasa de crecimiento de la economía estatal es mayor a la tasa de interés con la que el gobierno se endeuda, existirá espacio para ampliar el gasto gubernamental o reducir impuestos. En otras palabras, conforme se mantenga la tasa de interés por debajo de la tasa de crecimiento de la economía, un déficit primario positivo está asociado con una disminución gradual del saldo de la deuda pública.

Con la finalidad de aproximarse al costo de la deuda pública, una alternativa consiste en utilizar la tasa de interés $r$, calculando la tasa de interés implícita que queda expresada a continuación:

$$
r_{i t}=\frac{i n t_{i t}}{d_{i t-1}}
$$

En donde $r$ es la tasa de interés que se utilizará para el cálculo del espacio fiscal, la cual depende de la razón entre el pago de intereses int en la entidad $i$ en el año $t$ de la deuda pública y el saldo de la deuda del año inmediato anterior de la entidad $i$ en $t-1\left(d_{i t-1}\right)$.

\section{Fatiga fiscal}

Otra estrategia empírica para calcular el espacio fiscal consiste en estimar la diferencia entre el nivel actual de deuda pública y el límite de deuda obtenido a través del registro histórico de los ajustes fiscales realizados por la entidad correspondendiente (Ostry et al., 2010; Ghosh et al., 2011). Para obtenerlo, se estima la fatiga fiscal explicada como la falta de resistencia en el tiempo de los gobiernos para mantener balances primarios que se ajusten a los aumentos crecientes de deuda pública. Este argumento se muestra en la gráfica 4 . 
GRÁFICA 4. Fatiga fiscal y determinación del límite de la deuda

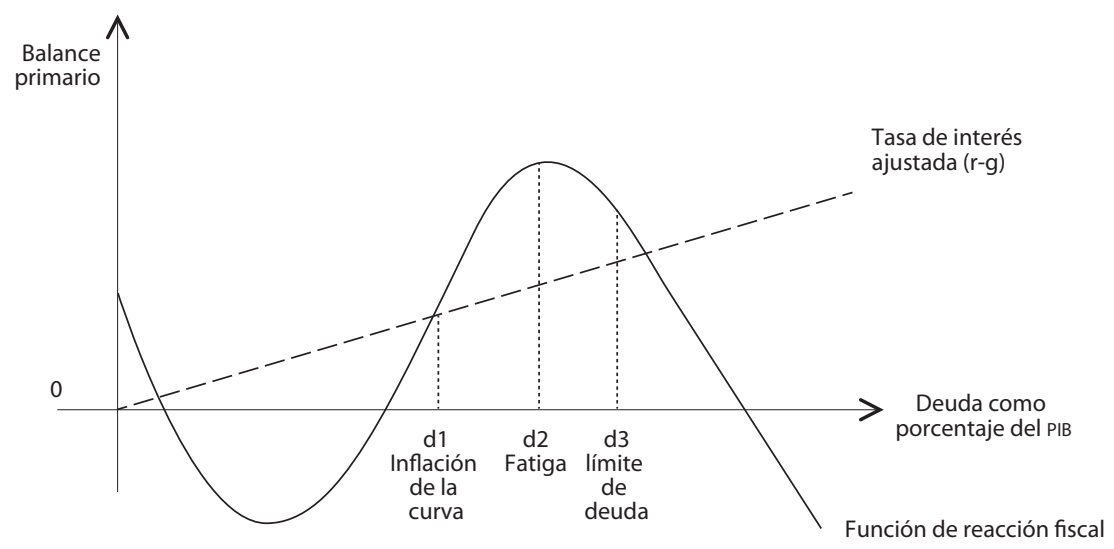

Fuente: Elaboración propia con base en Ghosh et al. (2011), y Bastos y Pineda (2013).

La fatiga fiscal se identifica, pues, en la respuesta del balance primario ante cambios en la deuda pública (como porcentaje del PIB), medido por la curva que mide la función de reacción fiscal en la gráfica 4. En un inicio, el balance primario responde positivamente cuando los niveles de deuda pública se mantienen bajos. Una vez que aumentan, los gobiernos pierden la capacidad de controlar los niveles de deuda por la vía del balance primario, hasta llegar a la fatiga en $d 2$, mostrando una trayectoria decreciente en la curva que mide la función de la reacción fiscal. En esta senda, el punto de insostenibilidad ocurre en $d 3$, momento a partir del cual los niveles de deuda comenzarían a aumentar sin límite alguno. Así, el espacio fiscal quedaría definido como la distancia entre el nivel actual de deuda del gobierno y el límite de deuda alcanzado en $d 3$.

La expresión algebraica de la fatiga fiscal se integra en la siguiente función cúbica (Ghosh et al., 2011):

$$
S_{t+1}=\mu+f(d)+\varepsilon_{t+1}
$$

Donde $\mu$ captura los determinantes sistémicos del balance primario que son distintos a la función de rezago de la deuda pública $f(d)$, y $\varepsilon_{t+1}$ es un shock independiente e idénticamente distribuido, acotado a $[\overline{-\varepsilon}, \bar{\varepsilon}]$.

De acuerdo con la restricción presupuestaria del gobierno, la intersección entre la función del balance primario y la diferencia entre la tasa de interés real 
( $r$ ) y la tasa de crecimiento de la economía en un periodo definido $(g)$ determina el límite de la deuda pública; en una condición de equlibrio en la cual los niveles de deuda se estabilizan, tal como se expresa a continuación:

$$
\left(r_{t}-g_{r}\right) d_{t}=\mu+f(d)+\varepsilon_{t+1}
$$

La estrategia metodológica consiste, entonces, en estimar la función cúbica de la deuda rezagada en la ecuación 4 e igualarla en 5 para obtener los límites de la deuda $\bar{d}$. Para este trabajo, esto se realiza, en primera instancia, a través de un modelo de regresión tipo panel con efectos fijos, para después utilizar los coeficientes obtenidos y, así, calcular los límites de deuda de las entidades federativas usando la ecuación 5 .

La estimación se realiza, para las entidades federativas, con datos anuales. En este sentido, la configuración del panel apunta a reducir los posibles sesgos, ya que los efectos fijos estimados recogen la heterogeneidad transversal no tratada. Aunado a lo anterior, la funcionalidad de los efectos fijos se reflejaría al incluirlos en la ecuación 5 para la estimación de los niveles de deuda de cada entidad federativa. En la siguiente ecuación se especifican las variables del modelo tipo panel, con efectos fijos a estimar:

$$
\begin{gathered}
S_{i t}=\alpha_{i}+\beta_{1} \operatorname{debt}_{i t}+\beta_{2} \operatorname{debt}_{i t}+\beta_{3} \operatorname{debt}_{i t}+g a p_{i t}+\operatorname{sgap}_{i t}+\text { inflation }_{i t}+ \\
+f v i_{i t}+e_{i t}
\end{gathered}
$$

Como ya se anticipaba, para el cálculo de los coeficientes necesarios para obtener los límites de deuda por entidad federativa $\bar{d}$ en la ecuación 5 , antes, se estima un modelo de regresión tipo panel con efectos fijos, en donde, de acuerdo con la ecuación 6, la variable dependiente $S_{i t}$ es el balance primario medido como porcentaje del producto interno bruto estatal en la entidad $i$, en el año $t$. Las variables dicotómicas para cada entidad federativa se expresan en $\alpha_{i}$; las variables explicativas de interés son la deuda pública como porcentaje del PIBE con rezago en debt1, al cuadrado en debt2, y al cubo en debt3. Al modelo se agregan las siguientes variables explicativas que, de acuerdo con la literatura, explicarían el comportamiento de los balances primarios: la brecha del producto interno bruto estatal $g a p_{i t}$, el componente cíclico del gasto público calculado como la brecha del gasto público $s g a p_{i t}$, la inflación inflation $_{i t}$ y el desbalance vertical medido como la ratio entre las transferencias (participaciones y aportaciones) y los ingresos totales de los gobiernos estatales fvi $i_{i t}$ (Bastos y Pineda, 2013; Mendoza y Ostry, 2008). Los términos de error se indican en $e_{i t}$. 


\section{Bases de datos}

Para el cálculo del espacio fiscal se utilizaron datos fiscales y económicos, anuales, provenientes del INEGI, para el periodo que abarca de 2003 a 2018. Los datos fiscales se tomaron de los registros administrativos y las cifras disponibles relacionadas con los indicadores de deuda pública de las entidades federativas y municipios, publicadas por la Secretaría de Hacienda y Crédito Pública (SHCP); mientras que el producto interno bruto estatal (PIBE) se tomó de las Cuentas Nacionales, tal como lo muestra el cuadro 2. Las cifras se trabajaron a precios constantes (2003 $=100$ ). Y las operaciones de gobierno, de las entidades federativas, se ajustaron a la clasificación económica propuesta en el Manual de Estadísticas de las Finanzas Públicas del FMI (2014), desagregando los ingresos y gastos, como se muestra en el cuadro 3.

CUADRO 2. Conformación de bases de datos y variables

Bases Fuente

Variables fiscales: operaciones de gobierno

- Balance primario: como porcentaje del PIBE

- Componente cíclico del gasto: diferencia entre el gasto tendencial y el gasto observado (se construyó con el filtro Hodrick-Prescott HP) (sgap)

- Desbalance vertical: ratio entre las transferencias y los ingresos totales (fvi)

Indicadores de deuda

- Deuda pública como porcentaje del PIBE (debt1_gdp, debt2_gdp, debt3_gdp)

- Tasa de interés promedio ponderada

\section{Cuentas nacionales}

- Brecha del PIBE: diferencia entre el PIBE tendencial y el PIBE observado (se construyó con el filtro Hodrick-Prescott HP) (gap)

Inflación anual (inflation)

\section{INEGI: Registros}

administrativos-Estadísticas económicas

- Finanzas públicas estatales y municipales

SHCP: Portal de disciplina financiera de las entidades federativas y municipios INEGI: Producto interno bruto - PIB por entidad federativa (PIBE)

Banco de México

Fuente: Elaboración propia.

CUADRO 3. Clasificación de los ingresos y gastos de los gobiernos estatales

\begin{tabular}{ll} 
Ingresos & Gastos \\
\hline Impuestos & Corriente \\
Transferencias & Pago de intereses de la deuda \\
Otros ingresos & Capital
\end{tabular}

Fuente: Elaboración propia con base en el MEFP (FMI, 2014). 
Estas variables, que se analizan en la teoría y en la práctica, son fundamentales para analizar las finanzas públicas locales en relación con su equilibrio fiscal inmediato; son una base para la sostenibilidad fiscal en el medio plazo.

Cabe señalar que los resultados de las variables — que se mencionan en el modelo- conllevan decisiones públicas que serán tomadas por los gerentes de los organismos. Estas decisiones no se reflejan abiertamente en el modelo; sin embargo, son variables proxys que puedan arrojar resultados comparables en los entes públicos subnacionales, tanto en la parte recaudatoria como en el ejercicio del gasto. Lo anterior puede llevar a no acelerar desequilibrios fiscales, dado que se pueden trasladar los pagos de deudas de los entes públicos en el futuro y ejecutar las políticas y programas en el presente. Por lo tanto, las instituciones son fundamentales para inhibir prácticas que debiliten la responsabilidad en la administración de la hacienda pública.

\section{EL ESPACIO FISCAL DE LOS GOBIERNOS ESTATALES}

\section{Espacio fiscal en términos del balance primario}

El espacio fiscal de los gobiernos estatales, en términos del balance primario disponible o requerido — durante el periodo analizado_- en promedio, se redujo cercano a cero; llegando incluso a requerirse (signo negativo) durante el periodo de 2010 a 2012, años en los que las entidades federativas resintieron el impacto de la crisis internacional.

Los niveles máximos de espacio fiscal disponible fueron de alrededor de 1.5 por ciento del PIBE; mientras que los niveles mínimos de espacio fiscal —siempre requeridos (-) - fueron, en promedio, de alrededor de -1.6 por ciento del PIBE. Destaca que, justamente en los años en los que el espacio fiscal promedio de las 32 entidades federativas resultó negativo, fue cuando las brechas entre los niveles máximos y mínimos alcanzaron su punto más alto. En efecto, la gráfica 3 evidencia que las disparidades de las cuentas fiscales entre entidades federativas aumentaron en el periodo 2010-2012.

Por entidad federativa, se observa que, durante el periodo analizado, las entidades con mejor comportamiento fueron Tlaxcala (0.63\%), Guanajuato $(0.56 \%)$, Aguascalientes (0.51\%) y el Estado de México (0.50\%); todas estas entidades, en promedio, lograron un balance primario disponible igual o superior a 0.5 por ciento del PIBE. En contraste, el grupo de entidades que registraron espacios fiscales requeridos fue liderado por Coahuila (-0.64\%), Nayarit (-0.36\%), Zacatecas $(-0.32 \%)$ y Morelos $(-0.31 \%)$; entidades que registraron un espacio fiscal negativo de magnitud igual o superior a los 0.3 puntos del PIBE. 
GRÁFICA 5. Espacio fiscal en los gobiernos estatales en términos del balance primario disponible o requerido, como porcentaje del PIBE (ecuación 1) (niveles máximos, promedio y mínimos)

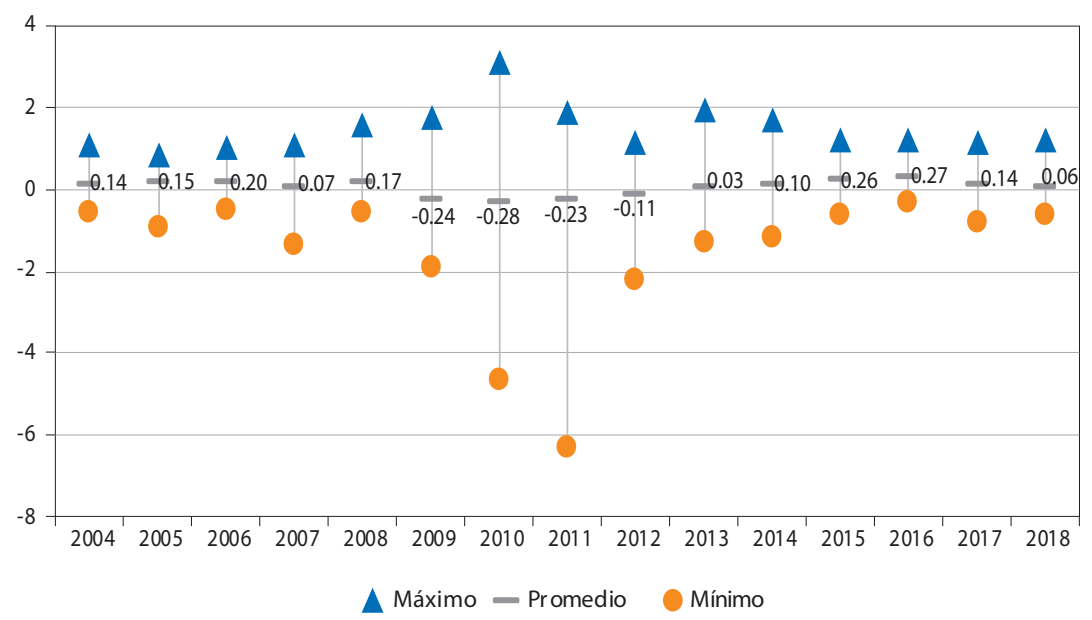

Fuente: Elaboración propia.

El cuadro 4 muestra los valores máximos, el promedio y el mínimo de los espacios fiscales registrados por cada entidad federativa durante el periodo analizado. Para más detalle, en el anexo 1 se presenta la evolución del espacio fiscal y la deuda pública por entidad federativa.

\section{Estimación de la fatiga fiscal}

Los resultados estimados en el modelo de regresión tipo panel con efectos fijos, expresado en la ecuación 6 , muestran consistencia respecto a lo encontrado en trabajos anteriores en lo concerniente a la respuesta del balance primario ante aumentos de la deuda pública con rezago (Bastos y Pineda, 2013; Ostry et al., 2010). En términos generales, al inicio, la reacción del balance primario es negativa frente a los aumentos de la deuda, mejorando marginalmente conforme la deuda se mantiene creciente, hasta llegar al punto de fatiga, que es cuando la reacción de los balances se vuelven negativos conforme aumenta la deuda pública estatal.

En los tres modelos estimados, los coeficientes de la deuda pública son significativos a 99, 95 y 90 por ciento de confianza según la etapa en que se encuentre 
CUADRO 4. Espacio fiscal en los gobiernos estatales en términos del balance primario disponible o requerido, como porcentaje del PIBE, periodo 2003-2018

\begin{tabular}{|c|c|c|c|}
\hline Entidad federativa & Máximo & Promedio & Minimo \\
\hline Aguascalientes & 1.4 & 0.5 & -1.4 \\
\hline Baja California & 0.1 & -0.2 & -0.4 \\
\hline Baja California Sur & 0.8 & 0.1 & -0.9 \\
\hline Campeche & 0.2 & 0.0 & -0.2 \\
\hline Chiapas & 2.0 & 0.3 & -0.9 \\
\hline Chihuahua & 0.5 & 0.0 & -1.0 \\
\hline Ciudad de México & 0.5 & 0.2 & 0.0 \\
\hline Coahuila & 0.5 & -0.6 & -6.3 \\
\hline Colima & 0.7 & 0.0 & -0.5 \\
\hline Durango & 0.3 & 0.0 & -0.6 \\
\hline Estado de México & 0.9 & 0.5 & 0.2 \\
\hline Guanajuato & 1.7 & 0.6 & -0.2 \\
\hline Guerrero & 0.8 & 0.2 & -0.6 \\
\hline Hidalgo & 1.2 & 0.3 & -0.9 \\
\hline Jalisco & 0.3 & 0.0 & -0.7 \\
\hline Michoacán & 1.2 & -0.1 & -1.9 \\
\hline Morelos & 0.6 & -0.3 & -1.3 \\
\hline Nayarit & 1.1 & -0.4 & -2.0 \\
\hline Nuevo León & 0.4 & 0.0 & -0.8 \\
\hline Oaxaca & 1.7 & 0.3 & -1.2 \\
\hline Puebla & 0.8 & 0.1 & -0.4 \\
\hline Querétaro & 0.8 & 0.2 & -0.3 \\
\hline Quintana Roo & 0.7 & -0.3 & -2.1 \\
\hline San Luis Potosí & 0.5 & 0.0 & -0.4 \\
\hline Sinaloa & 0.4 & 0.0 & -0.3 \\
\hline Sonora & 0.3 & -0.1 & -0.9 \\
\hline Tabasco & 1.1 & 0.1 & -0.9 \\
\hline Tamaulipas & 0.5 & -0.2 & -1.1 \\
\hline Tlaxcala & 3.1 & 0.6 & -0.4 \\
\hline Veracruz & 1.2 & 0.0 & -1.6 \\
\hline Yucatán & 0.3 & -0.1 & -0.9 \\
\hline Zacatecas & 0.8 & -0.3 & -2.2 \\
\hline
\end{tabular}

Fuente: Elaboración propia. 
la deuda pública. En debt 1 — con signo negativo—y debt2 — con signo positivo, pero con coeficientes bajos- la significancia siempre es a 99 por ciento de confianza. En debt3 — con signo negativo, pero, de igual forma, con los coeficientes bajos - la significancia en F1, F2 y F4 es a 95 por ciento de confianza; mientras que en F3 el coeficiente es significativo a 99 por ciento de confianza. El poder explicativo de los modelos estimados (r2_a) en F1 y F2 es de 31 por ciento, mejorando a 38 por ciento en F3 una vez incorporadas todas las variables de control, y empeorando a 24 por ciento en la estimación del modelo por efectos aleatorios en F4. Otras variables significativas que destacan son el componente cíclico del gasto público estatal, cuyo coeficiente, si bien es bajo, muestra una reacción negativa del balance primario a 99 por ciento de confianza en todos los modelos estimados; y el desbalance vertical, cuyos coeficientes en F3 y F4 son altos y significativos a 99 por ciento de confianza.

Los resultados de la prueba $\mathrm{F}$ de significancia de los efectos fijos, por su parte, indican que en F1, F2 y F3 las variables dicotómicas estatales sí pertenecen a los modelos estimados, lo que rechaza la hipótesis nula de que $\alpha_{i}=0$. Este resultado, en cierta forma, valida el método de efectos fijos implementado en los tres modelos.

Dado que el mayor poder explicativo se logró en F3, se estimó el modelo de efectos aleatorios en F4 con la finalidad de observar si las diferencias entre ambos modelos eran sistemáticas. Para ello, se realizó la prueba de Hausman, rechazándose la hipótesis nula de que no existen diferencias entre ambos modelos, tal como lo muestran los resultados en el anexo $2 \mathrm{a}$, donde se sugiere el uso del método de efectos fijos. Aunado a ello, se realizó la prueba de Wooldrige en F3, prueba cuyo resultado, mostrado en el anexo 2 b, no permite rechazar la hipótesis nula de autocorrelación de primer orden. Finalmente, se realizaron cuatro pruebas de raíz unitaria distintas, cuyos resultados, en el anexo $2 \mathrm{c}$, coinciden en rechazar la presencia de raíces unitarias en los paneles, validando con ello la estacionalidad de estos.

\section{Estimación del límite de deuda y espacio fiscal}

Con los coeficientes obtenidos en el cuadro 5, específicamente los obtenidos en F3, fue posible resolver el polinomio de tercer grado planteado en la ecuación 5 para cada entidad federativa. Para resolver la parte izquierda de la ecuación, se tomó en cuenta la media de la tasa de interés promedio ponderada, de las 32 entidades federativas, durante el periodo 2012-2018, y la tasa de crecimiento del PIBE, registrada para el mismo periodo, con lo que se obtiene una tasa de interés 
CUADRO 5. Resultado del modelo de regresión con efectos fijos. Cifras anuales: 2003-2018. 32 entidades federativas

\begin{tabular}{lcccc}
\hline $\begin{array}{l}\text { Variable dependiente: } \\
\text { balance primario como } \\
\text { porcentaje del PIB }\end{array}$ & $F 1$ & $F 2$ & $F 3$ & $\begin{array}{c}\text { F4 (efectos } \\
\text { aleatorios) }\end{array}$ \\
\hline debt1_gdp & & & & \\
debt2_gdp & $-0.2376942^{* * *}$ & $-0.2376942^{* * *}$ & $-0.2058332^{* * *}$ & $-0.2058463^{* * *}$ \\
debt3_gdp & $0.0000105^{* * *}$ & $0.0000105^{* * *}$ & $0.0000108^{* * *}$ & $8.85 \mathrm{E}-06^{* *}$ \\
gap & $-1.55 \mathrm{E}-10^{* *}$ & $-1.55 \mathrm{E}-10^{* *}$ & $-1.66 \mathrm{E}-10^{* * *}$ & $-1.36 \mathrm{E}-10^{* *}$ \\
sgap & $1.85 \mathrm{E}-06$ & $1.85 \mathrm{E}-06$ & $-1.37 \mathrm{E}-07$ & $2.60 \mathrm{E}-06$ \\
inflation & $-0.0001252^{* * *}$ & $-0.0001252^{* * *}$ & $-0.0001317^{* * *}$ & $-0.0001104^{* * *}$ \\
fvi & & 0.0489347 & 0.555198 & -0.0133665 \\
cons & & & $-6.04107^{* * *}$ & $-2.171221^{* * *}$ \\
N & 0.1324917 & -0.1214794 & 2.67654 & $2.120771^{* * *}$ \\
r2_a & 480 & 480 & 480 & 480 \\
Ftest & 0.31 & 0.31 & 0.38 & 0.24 \\
\hline
\end{tabular}

Fuente: Elaboración propia. Estimación con modelo de efectos fijos. ${ }^{* * *}$ Significativo a 99 por ciento de confianza, ${ }^{*}$ significativo a 95 por ciento de confianza, ${ }^{*}$ significativo al 90 por ciento de confianza.

real ajustada de $\mathrm{r}-\mathrm{g}=3.9$ por ciento; asimismo, se hizo el ejercicio asumiendo una tasa real ajustada $\mathrm{r}-\mathrm{g}=1$ por ciento. Para resolver el polinimio, también se incorporaron los efectos fijos y la constante estimada en F3. Así, la raíz más grande de cada ecuación es el límite de deuda para cada entidad federativa.

Los resultados obtenidos muestran que, en general, existe espacio fiscal en los gobiernos estatales de México, ya que en todos los casos los límites de deuda estimados son superiores a la deuda pública observada en 2018. Asimismo, es válido anticipar que los datos arrojados son consistentes con la evidencia previa obtenida para el caso de los gobiernos estatales de Brasil. En promedio, para las 32 entidades, la diferencia entre el límite de deuda estimado y la deuda observada en 2018 —el espacio fiscal, bajo este modelo— es de 10.2 puntos porcentuales del PIBE, cifra inferior en casi 2 puntos porcentuales a lo estimado para los estados brasileños - 12 puntos del PIB, aproximadamente- (Bastos y Pineda, 2013).

Si bien, en términos de límites de deuda pública, existe espacio fiscal en las entidades federativas, considerando el mediano y largo plazo, no deben dejarse 
de lado las heterogeneidades que ya se observan. Al mismo tiempo que existen estados que cuentan con un espacio superior o igual a los 15 puntos del PIBE - Tlaxcala y Aguascalientes_- también hay casos — como el de Quintana Roo y la Ciudad de México - cuyo espacio es apenas de o ligeramente superior a los 2 puntos porcentuales del PIBE.

CUADRO 6. Espacio fiscal en los gobiernos estatales, en términos del límite de deuda pública (ecuación 5), periodo 2003-2018

\begin{tabular}{|c|c|c|c|c|c|c|c|}
\hline Entidad & $\begin{array}{c}\text { Nivel máximo } \\
\text { de deuda } \\
\text { observado } \\
\% \text { del PIBE } \\
\text { (A) }\end{array}$ & $\begin{array}{l}\text { Nivel } \\
\text { minimo } \\
\text { de deuda } \\
\text { observado } \\
\text { \% del PIBE } \\
\text { (B) }\end{array}$ & $\begin{array}{l}\text { Limite de } \\
\text { deuda, } \\
\% \text { del PIBE } \\
r-g=3.9 \\
\text { (C) }\end{array}$ & $\begin{array}{l}\text { Limite de } \\
\text { deuda, } \\
\% \text { del PIBE } \\
r-g=1 \\
\text { (D) }\end{array}$ & $\begin{array}{l}\text { Deuda } \\
2018 \\
\% \text { del } \\
\text { PIBE } \\
(E)\end{array}$ & $\begin{array}{c}\text { Diferencia } \\
\text { entre peak } \\
\text { y 2018, en } \\
\text { puntos del } \\
\text { PIBE } \\
(A-E)\end{array}$ & $\begin{array}{c}\text { Espacio } \\
\text { fiscal, en } \\
\text { puntos del } \\
\text { PIBE } \\
(C-E)\end{array}$ \\
\hline Aguascalientes & 2.2 & 0.7 & 15.7 & 15.9 & 0.8 & 1.4 & 14.9 \\
\hline Baja California & 3.2 & 0.9 & 11.9 & 12.2 & 2.2 & 1.0 & 9.7 \\
\hline Baja California Sur & 2.2 & 0.7 & 13.8 & 14.0 & 0.7 & 1.5 & 13.1 \\
\hline Campeche & 0.5 & 0.0 & 12.2 & 12.3 & 0.5 & 0.0 & 11.8 \\
\hline Chiapas & 7.4 & 0.5 & 16.2 & 16.8 & 6.0 & 1.4 & 10.2 \\
\hline Chihuahua & 8.8 & 1.7 & 9.4 & 10.0 & 6.7 & 2.1 & 2.7 \\
\hline Ciudad de México & 3.0 & 2.2 & 4.4 & 4.7 & 2.3 & 0.8 & 2.1 \\
\hline Coahuila & 7.4 & 0.1 & 7.6 & 8.1 & 4.4 & 3.0 & 3.2 \\
\hline Colima & 3.2 & 1.0 & 14.0 & 14.3 & 2.8 & 0.5 & 11.2 \\
\hline Durango & 3.5 & 1.9 & 14.2 & 14.6 & 2.9 & 0.7 & 11.4 \\
\hline Estado de México & 4.8 & 2.2 & 8.8 & 9.3 & 2.2 & 2.6 & 6.7 \\
\hline Guanajuato & 1.7 & 0.4 & 14.9 & 15.0 & 0.5 & 1.1 & 14.3 \\
\hline Guerrero & 2.0 & 0.8 & 15.8 & 16.0 & 1.6 & 0.4 & 14.2 \\
\hline Hidalgo & 2.4 & 1.0 & 16.0 & 16.3 & 1.3 & 1.1 & 14.7 \\
\hline Jalisco & 2.7 & 1.1 & 12.5 & 12.8 & 1.2 & 1.6 & 11.4 \\
\hline Michoacán & 4.6 & 0.8 & 12.1 & 12.6 & 3.7 & 1.0 & 8.5 \\
\hline Morelos & 3.0 & 0.2 & 12.9 & 13.1 & 2.1 & 0.9 & 10.7 \\
\hline Nayarit & 6.4 & 0.2 & 12.7 & 13.1 & 3.8 & 2.5 & 8.8 \\
\hline Nuevo León & 5.1 & 1.6 & 10.1 & 10.6 & 4.3 & 0.8 & 5.8 \\
\hline Oaxaca & 4.6 & 0.3 & 16.0 & 16.3 & 4.4 & 0.2 & 11.6 \\
\hline Puebla & 2.2 & 0.7 & 13.8 & 14.0 & 0.7 & 1.5 & 13.1 \\
\hline Querétaro & 1.2 & 0.1 & 13.5 & 13.6 & 0.1 & 1.1 & 13.4 \\
\hline
\end{tabular}


CUADRO 6. Espacio fiscal en los gobiernos estatales, en términos del límite de deuda pública (ecuación 5), periodo 2003-2018 (continuación)

\begin{tabular}{|c|c|c|c|c|c|c|c|}
\hline Entidad & $\begin{array}{c}\text { Nivel máximo } \\
\text { de deuda } \\
\text { observado } \\
\% \text { del PIBE } \\
\text { (A) }\end{array}$ & $\begin{array}{l}\text { Nivel } \\
\text { minimo } \\
\text { de deuda } \\
\text { observado } \\
\% \text { del PIBE } \\
\text { (B) }\end{array}$ & $\begin{array}{l}\text { Limite de } \\
\text { deuda, } \\
\% \text { del PIBE } \\
r-g=3.9 \\
(C)\end{array}$ & $\begin{array}{l}\text { Limite de } \\
\text { deuda, } \\
\% \text { del PIBE } \\
r-g=1 \\
\text { (D) }\end{array}$ & $\begin{array}{l}\text { Deuda } \\
2018 \\
\% \text { del } \\
\text { PIBE } \\
(E)\end{array}$ & $\begin{array}{c}\text { Diferencia } \\
\text { entre peak } \\
\text { y 2018, en } \\
\text { puntos del } \\
\text { PIBE } \\
(A-E)\end{array}$ & $\begin{array}{c}\text { Espacio } \\
\text { fiscal, en } \\
\text { puntos del } \\
\text { PIBE } \\
(C-E)\end{array}$ \\
\hline Quintana Roo & 8.6 & 1.4 & 7.8 & 8.5 & 5.7 & 3.0 & 2.2 \\
\hline San Luis Potosí & 2.1 & 0.7 & 13.3 & 13.5 & 0.7 & 1.4 & 12.6 \\
\hline Sinaloa & 2.3 & 1.1 & 13.4 & 13.7 & 1.1 & 1.2 & 12.3 \\
\hline Sonora & 4.5 & 2.0 & 9.9 & 10.3 & 3.3 & 1.2 & 6.5 \\
\hline Tabasco & 1.3 & 0.2 & 14.8 & 14.8 & 0.9 & 0.4 & 13.8 \\
\hline Tamaulipas & 2.6 & 0.2 & 12.2 & 12.4 & 1.8 & 0.8 & 10.4 \\
\hline Tlaxcala & 0.4 & 0.0 & 16.5 & 16.5 & 0.0 & 0.4 & 16.5 \\
\hline Veracruz & 5.4 & 0.5 & 11.5 & 12.0 & 4.4 & 1.0 & 7.1 \\
\hline Yucatán & 1.3 & 0.3 & 13.0 & 13.1 & 1.1 & 0.2 & 11.9 \\
\hline Zacatecas & 4.6 & 0.1 & 12.4 & 12.8 & 4.2 & 0.5 & 8.3 \\
\hline Promedio nacional & 3.6 & 0.8 & 12.6 & 12.9 & 2.5 & 1.2 & 10.2 \\
\hline
\end{tabular}

Fuente: Elaboración propia.

\section{CONCLUSIONES Y RECOMENDACIONES DE POLÍTICA PÚBLICA}

Si bien es reconocido ampliamente, en la literatura, que el financiamiento de los gobiernos subnacionales es una pieza clave para potenciar el desarrollo de países como México - a través de la provisión de bienes y servicios y el aumento de la inversión-, poco se discute sobre la sostenibilidad fiscal que estos gobiernos requieren para lograrlo.

El presente trabajo ha intentado contribuir a esta conversación, recurriendo al análisis y determinación del espacio fiscal, como medida necesaria para hacer ajustes (por la vía del gasto o del ingreso) sin alterar la posición financiera de los gobiernos estatales, como supuesto principal.

Como resultado, se observó que, en las últimas décadas, los gobiernos estatales mexicanos han enfrentado un espacio fiscal reducido, en términos de sus balances primarios, llegando incluso a ser negativo, dependiendo del periodo que 
se analice. Este comportamiento tiene que ver - tal como se documenta en la evidencia previa - con la falta de correspondencia entre responsabilidades de gasto adquiridas en el marco de descentralización actual y la poca capacidad legal y administrativa que estos gobiernos han desarrollado para generar recursos propios que les permitan atender las necesidades locales.

En lo que respecta a la estrategia metodológica empleada, se mostró que, de manera consistente con la literatura (Bastos y Pineda, 2013; Ostry et al., 2010), el comportamiento de los gobiernos estatales podría manifestar cierta fatiga, en el medio y largo plazo, que le impediría mantener resultados primarios sostenibles en correspondencia con los crecientes niveles de deuda. Este hallazgo advierte acerca de una situación de desequilibrios fiscales que irían en detrimento del financiamiento y la ejecución de políticas públicas locales.

Sin embargo, en términos de deuda pública estatal, los resultados evidencian que aún existe espacio fiscal en todos los gobiernos estatales, dado que el nivel de deuda alcanzado en términos del PIBE, en 2018, en todas las entidades federativas, se encuentra por debajo de los límites de deuda estimados, y a partir de los cuales los gobiernos caerían en niveles de insostenibilidad. Destacan, no obstante, las amplias diferencias de espacio fiscal que existen entre los estados, característica que evidencia las desigualdades presentes en cuanto a presiones de gasto, de capacidades institucionales y de gestión del financiamiento para las políticas públicas locales.

De acuerdo con la evidencia, el espacio fiscal, en el límite de deuda, podría utilizarse para promover el acceso a financiamientos vía crédito, que impulsen las economías locales a través del gasto social y de inversión pública, en condiciones propicias materializadas en bajas tasas de interés y otros costos de la deuda. Este resultado, asimismo, respalda de cierta forma la necesidad de discutir el uso y aprovechamiento de la deuda estatal garantizada (DEG) como un instrumento jurídico mediante el cual el gobierno federal avala el pago de las obligaciones constitutivas de deuda pública de los estados y municipios, reduciendo tanto la probabilidad de incumplimiento como, en efecto, el costo de las obligaciones. ${ }^{6}$

Los esfuerzos de este trabajo apuntan a contribuir metodológicamente en el debate y la construcción de evidencia que pueda utilizarse como una línea base para evaluar, en términos cuantificables, los efectos de la Ley de Disciplina Financiera

\footnotetext{
${ }^{6}$ Este instrumento se incorporó en la Ley de Disciplina Financiera de las Entidades Federativas y los Municipios y cuenta con lineamientos específicos que delimitan el propio riesgo que asumiría la federación al otorgar dicha garantía: la fuente primaria de pago son las participaciones federales de la entidad; la federación no puede avalar deuda más allá de 100 por ciento de los ingresos de libre disposición de la entidad, y, en total, la DEG que garantice la federación no puede sobrepasar 3.5 por ciento del PIB (Andrade, 2018).
} 
de las Entidades Federativas y los Municipios, aprobada en 2016, en los resultados fiscales de los gobiernos estatales. Hasta el momento, se han documentado resultados positivos en términos de transparencia de los financiamientos y obligaciones contratadas, también en las mejores tasas de interés, así como en el procesamiento de mayor y más confiable información contable y financiera (Andrade, 2018); sin embargo, aún resta evaluar empíricamente los efectos que esta ley pueda tener en la sostenibilidad de las cuentas públicas de los gobiernos estatales.

Derivado de los resultados, es recomendable discutir medidas y cambios en la Ley de Disciplina Financiera para las Entidades Federativas y los Municipios y la Ley de Coordinación Fiscal, que promuevan la igualdad en las condiciones de acceso a financiamiento y que, a la par, incentiven el esfuerzo fiscal de los estados y municipios, teniendo en cuenta las condiciones regionales que determinan las disparidades actuales; apuntando, con ello, a un equilibrio de medio y largo plazo entre responsabilidades de gasto descentralizadas y la generación de ingresos fiscales propios.

Finalmente, queda como desafío, para investigaciones futuras, discutir y desarrollar propuestas metodológicas para darle cauce al espacio fiscal, analizando los objetivos del gasto público subnacional y la forma en que este puede repercutir en el bienestar de la población, a través de políticas sociales e inversiones en infraestructura que dinamicen el crecimiento. $\mathbf{G} \hat{\mathrm{a}}$

\section{REFERENCIAS}

Aguilar, G. (2010), "Capacidad tributaria y finanzas públicas metropolitanas en México", Estudios Demográficos y Urbanos, 25(1), pp. 103-132.

Andrade, M. (2018), La reforma en materia de disciplina financiera de entidades federativas y los municipios, Ciudad de México, Fondo de Cultura Económica.

Ángeles, G., M. Salazar y L. Contreras (2019), "Federalismo fiscal y su efecto en el crecimiento y la distribución de ingresos. Evidencia para México", Gestión y Política Pública, XXVIII(1), pp. 107-139.

Bahl, R. y J. Linn (1992), Urban Public Finance in Developing Countries, Washington, D.C., Banco Mundial.

Baum A., A. Hodge, A. Mineshima, M. Moreno-Badía y R. Tapsoba (2017), "Can They Do It All? Fiscal Space in Low-Income Countries”, documento de trabajo WP/17/110, FMI.

Bonet, J. y F. Rueda (2012), "Esfuerzo fiscal en los estados mexicanos", documento de trabajo, Banco Interamericano de Desarrollo.

Bossuyt, J. (2013), "Overview of the Decentralisation Process in Latin America: Main Achievements, Trends and Future Challenges", documento de discusión 148, ECDPM. 
Brennan, G. y J. Buchanan (1980), The Power to Tax: Analytical Foundations of Fiscal Constitution, Cambridge, Cambridge University Press.

Breton, A. (1998), Competitive Governments: An Economic Theory of Politics and Public Finance, Cambridge, Cambridge University Press.

Broid, D. (2010), "La evolución del predial en México: Los incentivos cruzados de la descentralización fiscal y política, 1990-2007”, Finanzas Públicas, 2(3-4), pp. 69-192.

Brosio, G. y J. Jiménez (2012), "Introduction: Approaching Recent Transformations of Intergovernmental Relations from Multiple Profiles”, en G. Brosio y J.P. Jiménez (eds.), Decentralization and Reform in Latin America: Improving Intergovernmental Relations, Cheltenham, Edward Elgar Publishing, pp. 290-320.

Buchanan, J. (1965), "An Economic Theory of Clubs", Economica, 32(125), pp. 1-14.

Bastos, F. y E. Pineda (2013), "Fiscal Space of Brazilian States", documento de discusión IDB-DP-310, Banco Interamericano de Desarrollo.

Cabrero, E. (2004), "Capacidades institucionales en gobiernos subnacionales de México ¿Un obstáculo para la descentralización fiscal?”, Gestión y Política Pública, XIII(3), pp. 753-784.

Cabrero, E. (2013), "Fiscal Federalism in Mexico: Distortions and Structural Traps", Urban Public Economics Review, 18, pp. 12-36.

Cámara de Diputados (1978), Ley de Coordinación Fiscal, última reforma, 2018, disponible en: http://www.diputados.gob.mx/LeyesBiblio/pdf/31_300118.pdf [fecha de consulta: 9 de diciembre de 2019].

Cámara de Diputados (2016), Ley de Disciplina Financiera de las Entidades Federativas y los Municipios, última reforma, 2018, disponible en: http:/www.diputados.gob.mx/ LeyesBiblio/pdf/LDFEFM_300118.pdf [fecha de consulta: 9 de diciembre de 2019].

Cárdenas, S. (2013), "Investigación sobre el financiamiento de la educación básica”, en A. Maldonado (coord.), Educación y ciencia: Políticas y producción de conocimiento 20022011, Ciudad de México, anuies, pp. 469-483.

Cárdenas, O. y F. Luna (2007), "El gasto educativo: Una propuesta de financiamiento a la educación básica”, Gestión y Politica Pública, XVI(2), pp. 261-279.

CEFP (Centro de Estudios de las Finanzas Públicas) (2017), Criterios que se utilizan para la asignación presupuestal a entidades federativas y municipios en la Ley de Coordinación Fiscal, Ciudad de México, Cámara de Diputados, LXIII Legislatura-CEFP.

Chávez, L. (2014), "Desistimiento fiscal, incertidumbre y propiedad social en los municipios de México", Región y Sociedad, 26(61), pp. 87-117.

Espinosa, S., J. Martínez y C. Martell (2018), “¿Por qué algunos municipios en México son mejores recaudadores de impuesto predial que otros?”, Gestión y Política Pública, XXVII(2), pp. 375-395. 
FMI (Fondo Monetario Internacional) (2014), Manual de estadísticas de finanzas públicas, Washington, D.C., FMI.

FMI (Fondo Monetario Internacional) (2018), "Assessing Fiscal Space: An Update and Stocktaking”, documento de política pública, Washington, D.C., FMI.

Gámez, C. y A. Ibarra-Yúnez (2009), "El ciclo político y oportunista y el gasto de los estados mexicanos", Gestión y Politica Pública, XVIII(1) pp. 39-65.

Ganiko, G., K. Melgarejo y C. Montoro (2016), "Estimación del espacio fiscal en economías emergentes: El caso peruano", documento de investigación 001-2016, Consejo Fiscal del Perú.

Ghosh, A., J. Kim, E. Mendoza, J. Ostry y M. Qureshi (2011), "Fiscal Fatigue, Fiscal Space and Debt Sustainability in Advanced Economies", documento de trabajo 16782, NBER.

Gómez, J. y J. Jiménez (2017), “La tributación en los gobiernos subnacionales”, en J. Gómez, J. Jiménez y R. Martner (eds.), Consensos y conflictos en la política tributaria de América Latina, Santiago de Chile, CEPAL/onu, pp. 93-117.

González, J. (2005), "La descentralización de la educación básica en México: El impacto sobre las finanzas y el endeudamiento de los estados", Ciudad de México, Instituto Tecnológico Autónomo de México.

Guillermo, S. e I. Vargas (2017), "Recaudación potencial, eficiencia recaudatoria y transferencias federales: Un análisis para las entidades federativas en México utilizando el modelo de frontera estocástica”, EconoQuantum, 14(1), pp. 35-71.

Heller, P. (2005), “Understanding Fiscal Space”, documento de discusión de política pública PDP/05/4, FMI.

Ibarra, J. (2013), "Entorno político y dependencia financiera de los estados mexicanos", Gestión y Politica Pública, XXII(1), pp. 3-44.

INEGI (Instituto Nacional de Estadística y Geografía) (2019), Sistema de cuentas nacionales de México: Cuentas de bienes y servicios (detallada), disponible en: https://datos.gob.mx/ busca/dataset/sistema-de-cuentas-nacionales-de-mexico-producto-interno-bruto-pib/ resource/b2085383-75b4-4ad8-af15-562143530dbb [fecha de consulta: 9 de diciembre de 2019].

INEGI (Instituto Nacional de Estadística y Geografía) (2020), Finanzas públicas estatales y municipales, 15 de mayo, disponible en: https:/www.inegi.org.mx/programas/finanzas/ [fecha de consulta: 9 de diciembre de 2019].

Jiménez, J. e I. Ruelas (2016), El endeudamiento de los gobiernos subnacionales en América Latina: Evolución, institucionalidady desafios, Santiago de Chile, ONU/CEPAL.

Jiménez, J. e I. Ruelas (2018), “Autonomía tributaria subnacional en América Latina”, Presupuesto y Gasto Público, 92, pp. 177-197. 
Larios, J., B. Alvarado y E. Conterno (eds.) (2004), “Descentralización fiscal”, documento técnico 7, Lima, Agencia de los Estados Unidos para el Desarrollo Internacional.

León-Alfonso, S. (2006), "The Political Economy of Fiscal Descentralization: Bringing Politics to the Study of Intergovernmental Transfers", tesis doctoral, Universidad Autónoma de Madrid.

Lozano-Espitia, I. y J. Julio-Román (2019), "Límite de la deuda pública y espacio fiscal: Análisis para Colombia y otros mercados emergentes”, Borradores de Economía 1076.

Meléndez, K. (2019), Estimación de tenencia potencial 2019, Ciudad de México, Centro de Investigación Económica y Presupuestaria, disponible en: https://ciep.mx/estimacionde-tenencia-potencial-2019/ [fecha de consulta: 9 de diciembre de 2019].

Mendoza, E. y J. Ostry (2008), "International Evidence on Fiscal Solvency: Is Fiscal Policy 'responsible'?" Journal of Monetary Economics, 55(6), pp. 1081-1093.

Musgrave, R. (1959), The Theory of Public Finance: A Study in Public Economy, Nueva York, McGraw-Hill.

Oates, W. (1972), Fiscal Federalism, Nueva York, Harcourt Brace Jovanovich.

Oates, W. (2008), "On the Evolution of Fiscal Federalism: Theory and Institutions”, National Tax Journal, 61(2), pp. 313-334.

Olson, M. (1969), "The Principle of 'Fiscal Equivalence': The Division of Responsibilities among Different Levels of Government", American Economic Review, 59(2), pp. 479-487.

Ostry, J., A. Ghosh, J. Kim y M. Qureshi (2010), Fiscal Space, nota de posición del personal SPN/10/11, FMI.

OCDE (Organización para la Cooperación y el Desarrollo Económicos), CIAT (Centro Interamericano de Administraciones Tributarias), BID (Banco Interamericano de Desarrollo) y Cepal (Comisión Económica para América Latina y el Caribe) (2020), Estadísticas tributarias en América Latina y el Caribe 1990-2018, París, OCDE.

Ornelas, C. (2018), La contienda por la educación: Globalización, neocorporativismo y democracia, Ciudad de México, Fondo de Cultura Económica.

Prud'homme, R. (1995), "The Dangers of Decentralisation", The World Bank Research Observer, 10(2), pp. 201-210.

Ramírez, R. y A. Erquizio (2011), "Capacidad y esfuerzo fiscal en las entidades federativas en México: medición y determinantes", Paradigma Económico, 3(1), pp. 37-70.

Rothenberg, J. (1970), "Local Decentralization and the Theory of Optimal Government Comment", en J. Margolis (ed.), The Analysis of Public Output, umI, pp. 31-68.

Ruelas I. (2015), "Evaluación de las características del impuesto predial en México", Revista Iberoamericana de Estudios Municipales, 6(12), pp. 67-102.

Sepúlveda, C. y J. Martinez-Vazquez (2012), "Explaining Property Tax Collections in Developing Countries: The case of Latin American”, en G. Brosio y J. Jiménez (eds.), 
Descentralization and Reform in Latin America: Improving Intergovernmental Relations, Chetelham, Edward Elgar, pp. 172-222.

SHCP (Secretaría de Hacienda y Crédito Público) (2016), Portal de Disciplina Financiera de las Entidades Federativas y Municipios, disponible en: https://www.disciplinafinanciera. hacienda.gob.mx/ [fecha de consulta: agosto de 2020].

Sobarzo, H. (2004), "Federalismo fiscal en México", Economía, Sociedady Territorio, 5 (extra 1), pp. 103-121.

Soria, R. (2018), "Una estimación del costo de la inseguridad y la delincuencia en México: Análisis comparativo a nivel de las entidades federativas", Gestión y Politica Pública, XXVII(1), pp. 111-147.

Sour, L. (2008), "Un repaso sobre los conceptos sobre capacidad y esfuerzo fiscal, y su aplicación en los gobiernos locales mexicanos”, Estudios Demográficos y Urbanos, 23(2), pp. 271-297.

Sovilla, B., A. Saragos y E. Morales (2018), "Contradicciones de la descentralización fiscal en México: El caso de Chiapas”, Gestión y Política Pública, XXVII(2), pp. 397-429.

StataCorp (s.f.), xtunitroot: Panel-data unit-root tests, disponible en: https://www.stata.com/ manuals13/xtxtunitroot.pdf [fecha de consulta: 9 de diciembre de 2019].

Terman, J. y R. Feiock (2015), "Improving Outcomes in Fiscal Federalism: Local Political Leadership and Administrative Capacitiy", Journal of Public Administration Research and Theory, 25(4), pp. 1059-1080.

Tiebout, C. (1956), “A Pure Theory of Local Expenditures", Journal of Political Economy, 64(5), pp. 416-424.

Tiebout, C. (1961), “An Economic Theory of Fiscal Decentralization”, Public Finances: Needs, Sources, and Utilization, pp. 79-96.

Tirole, J. (1994). "The International Organization of Government", Oxford Economic Papers, 46(1), pp. 1-29.

Trujillo, J. (2013), El FAEB: ¿Asignación equitativa?, Xalapa, Secretaría de Educación del Estado de Veracruz.

Tullock, G. (1969), "Federalism: Problems of Scale”, Public Choice, 6, pp. 19-29.

Valenzuela-Reynaga, R. y A. Hinojosa-Cruz (2017), "Las transferencias federales, los contrapesos políticos y los ingresos fiscales estatales en México", EconomíaUNAM, 14(42), pp. 47-71.

Weingast, B. (1995), "The Economic Role of Political Institutions: Market-Preserving Federalism and Economic Development", Journal of Law, Economics and Organization, 11(1), pp. 1-31.

Weingast, B. (2008), "Second Generation Fiscal Federalism: The Implications of Fiscal Incentives", Journal of Urban Economics, 65(3), pp. 279-293.

Willis, E., C. Garman, y S. Haggard (1999), "The Politics of Decentralization in Latin America”, Latin American Research Review, 34(1), pp. 7-56. 


\section{ANEXO 1}

Entidades federativas: evolución del espacio fiscal en términos de la disponibilidad del balance primario (fs) y la deuda pública estatal (debt_gdp), como porcentaje del PIBE.

a)
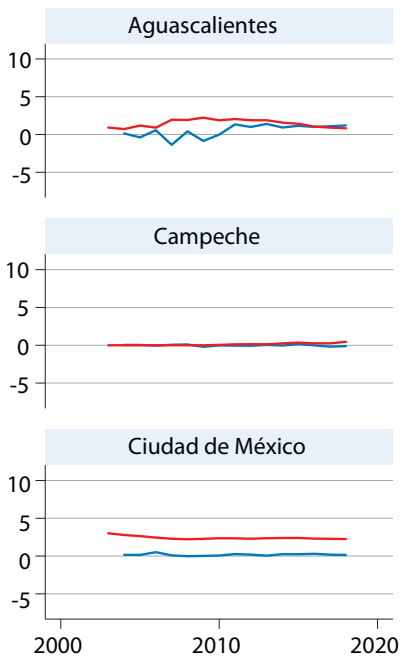

Gráficas por estado

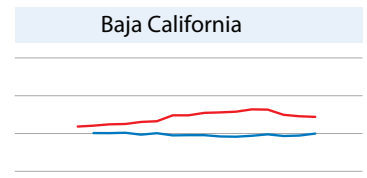

Chiapas

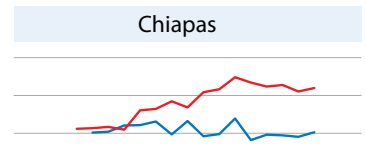

Coahuila de Zaragoza

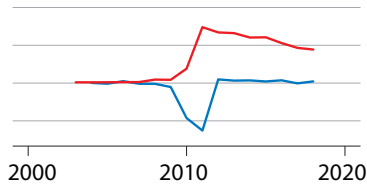

Año
Baja California Sur

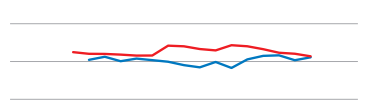

Chihuahua

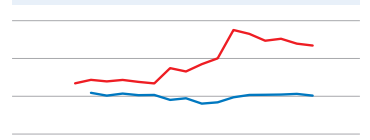

Colima

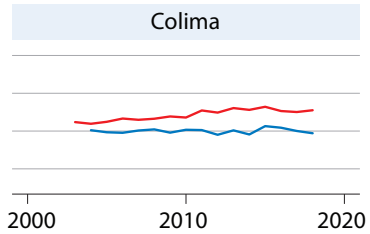

Fuente: Elaboración propia con base en datos de la SHCP (Portal de Disciplina Financiera de las Entidades Federativas y Municipios) e INEGI (Registros administrativos-Estadísticas económicas). 
Fatiga, límites de deuda y espacio fiscal de los gobiernos estatales en México

b)
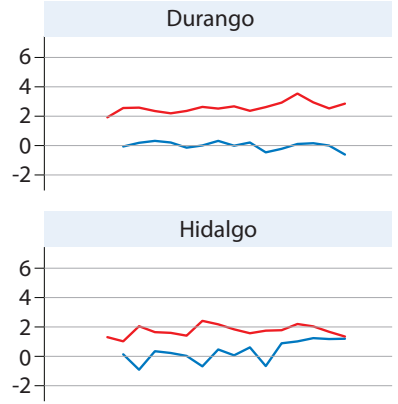

Morelos

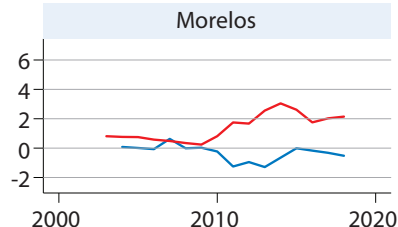

Gráficas por estado

c)

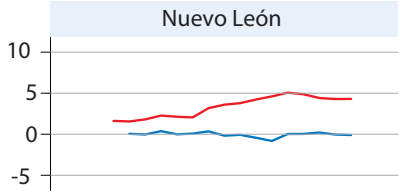

Querétaro
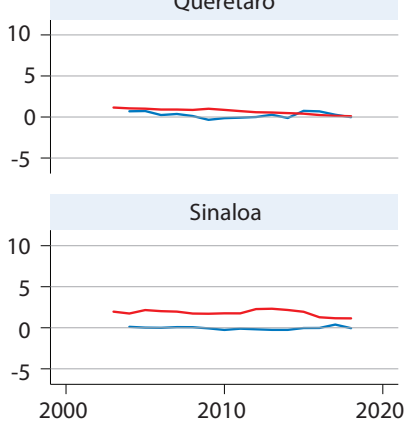

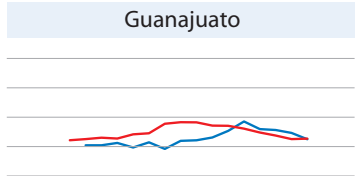

Jalisco

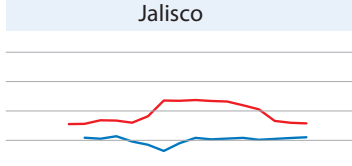

México

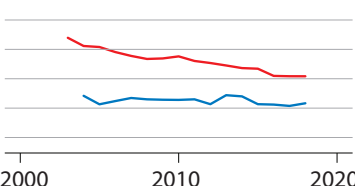

Año
Guerrero

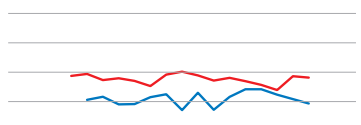

Michoacán de Ocampo

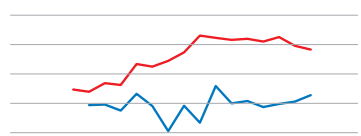

Nayarit

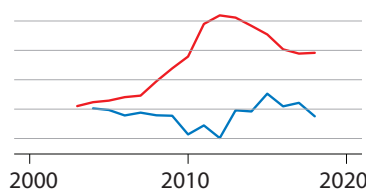

2020
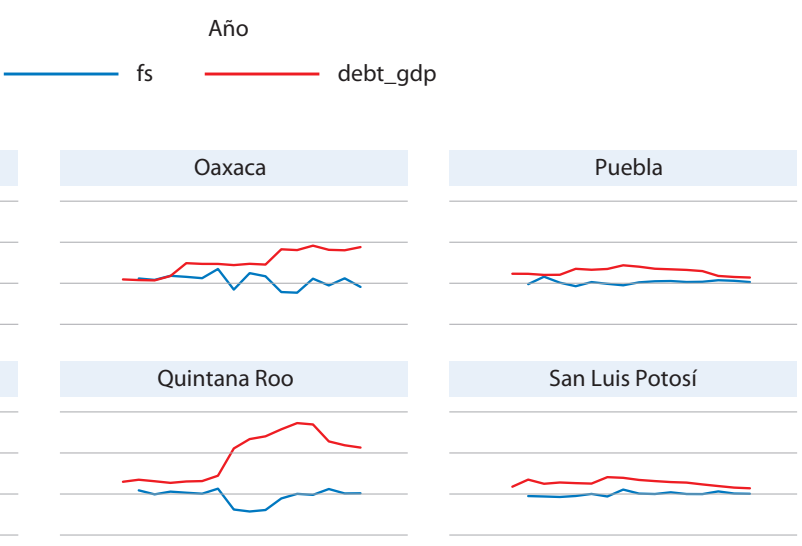

Sonora

Tabasco
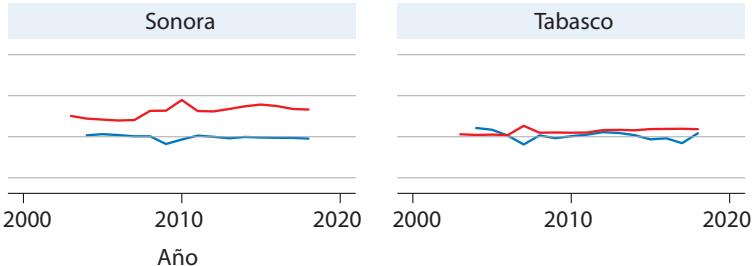

Gráficas por estado fs debt_gdp

Fuente: Elaboración propia con base en datos de la SHCP (Portal de Disciplina Financiera de las Entidades Federativas y Municipios) e INEGI (Registros administrativos-Estadísticas económicas). 
d)
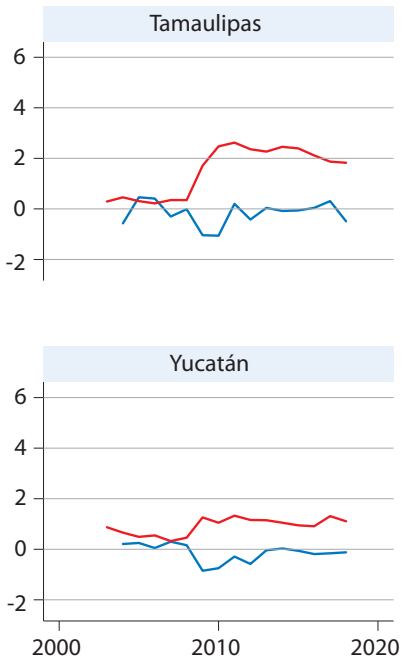

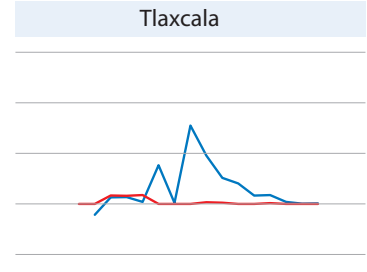

\section{Veracruz de Ignacio de la Llave}

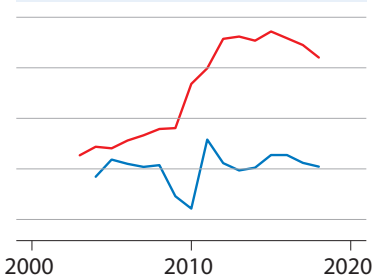

Zacatecas

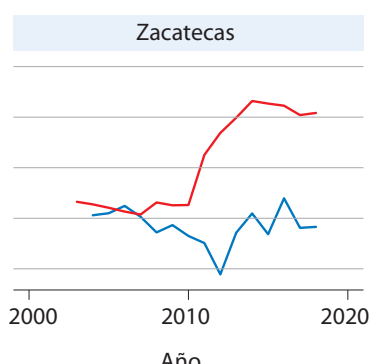

Año

Gráficas por estado

fs

debt_gdp

Fuente: Elaboración propia con base en datos de la SHCP (Portal de Disciplina Financiera de las Entidades Federativas y Municipios) e INEGI (Registros administrativos-Estadísticas económicas). 


\section{ANEXO 2}

a) Prueba de Hausman

Prueba de Hausman

\begin{tabular}{lccc}
\hline Variable & $\begin{array}{c}\text { Coeficiente en } \\
F 3(b)\end{array}$ & $\begin{array}{c}\text { Coeficiente en F4 } \\
\text { (efectos aleatorios) } \\
(B)\end{array}$ & $\begin{array}{c}\text { Diferencia } \\
(b-B)\end{array}$ \\
\hline debt1_gdp & -0.2058332 & -0.2058463 & 0.0000131 \\
debt2_gdp & 0.0000108 & $8.85 \mathrm{E}-06$ & $2.00 \mathrm{E}-06$ \\
debt3_gdp & $-1.66 \mathrm{E}-10$ & $-1.36 \mathrm{E}-10$ & $-3.05 \mathrm{E}-11$ \\
gap & $-1.37 \mathrm{E}-07$ & $2.60 \mathrm{E}-06$ & $-2.73 \mathrm{E}-06$ \\
sgap & -0.0001317 & -0.0001104 & -0.0000213 \\
inflation & 0.555198 & -0.0133665 & 0.5685645 \\
fvi & -6.04107 & -2.171221 & -3.869849 \\
chi2(3) $=(\mathrm{b}-\mathrm{B})^{\prime}\left[\left(\mathrm{V} \_\mathrm{b}-\mathrm{V} \text {-B_B }\right)^{\wedge}(-1)\right](\mathrm{b}-\mathrm{B})$ & 38.59 & & \\
Prob>chi2 $=$ & 0.000 & & \\
\hline
\end{tabular}

Fuente: Elaboración propia.

\section{b) Prueba de Wooldrige}

Prueba de Wooldridge

\begin{tabular}{lrcc}
\hline Variable & Coeficiente & Estadistico $t$ & $P>|t|$ \\
\hline debt1_gdp (D1.) & -0.0409829 & -0.24 & 0.813 \\
debt2_gdp (D1.) & 0.0000125 & 0.99 & 0.329 \\
debt3_gdp (D1.) & $-1.77 \mathrm{E}-10$ & -0.97 & 0.341 \\
gap (D.1) & $-8.44 \mathrm{E}-07$ & -0.32 & 0.748 \\
sgap (D.1) & -0.0000978 & -3.49 & 0.001 \\
inflation (D.1) & 0.0138765 & 0.74 & 0.462 \\
fvi (D.1) & -5.855671 & -3.22 & 0.003 \\
r2_a & 0.2967 & & \\
$\mathrm{~N}$ & 448 & & \\
Prueba de Wooldridge & $\mathrm{F}(1,31)=2.440$ & & \\
& Prob $>\mathrm{F}=0.1284$ & & \\
\hline
\end{tabular}

Fuente: Elaboración propia. 
c) Pruebas de raíz unitaria del modelo tipo panel, con efectos fijos

Pruebas de raíz unitaria

Variable dependiente: balance primario como porcentaje del PIBE

\begin{tabular}{|c|c|c|c|}
\hline Prueba & Caracteristica & Estadístico & Valor de P \\
\hline $\begin{array}{l}\text { Levin-Lin-Chu unit- } \\
\text { root test }\end{array}$ & $\begin{array}{l}\text { Se recomienda su uso con paneles de } \\
\text { tamaño"moderado", característica que } \\
\text { abarca de } 10 \text { a } 250 \text { paneles y de } 25 \text { a } \\
250 \text { observaciones por panel. }\end{array}$ & Tajustada $=-5.9695$ & 0.000 \\
\hline $\begin{array}{l}\text { Fisher-type tests } \\
\text { (Basado en pruebas } \\
\text { Dickey-Fuller } \\
\text { aumentadas) }\end{array}$ & $\begin{array}{l}\text { En el contexto de las pruebas de raíz } \\
\text { unitaria de datos de panel, se realiza } \\
\text { una prueba de raíz unitaria en la serie } \\
\text { de cada panel por separado; luego, se } \\
\text { combinan los valores } p \text { para obtener } \\
\text { una prueba general que valide si } \\
\text { la serie de panel contiene una raíz } \\
\text { unitaria. }\end{array}$ & Inverse normal $(Z)=-13.8524$ & 0.000 \\
\hline Breitung unit-root test & $\begin{array}{l}\text { La prueba de Breitung tiene buen } \\
\text { poder incluso en paneles pequeños, } \\
\text { aunque la potencia de la prueba } \\
\text { parece deteriorarse cuando T se fija y N } \\
\text { aumenta. }\end{array}$ & lambda $=-7.9085$ & 0.000 \\
\hline $\begin{array}{l}\text { Im-Pesaran-Shin unit- } \\
\text { root test }\end{array}$ & $\begin{array}{l}\text { La prueba IPS permite paneles } \\
\text { heterogéneos con errores no } \\
\text { correlacionados en serie, y asume que } \\
\text { el número de periodos de tiempo, } \mathrm{T} \text {, } \\
\text { es fijo; xtunitroot ips produce pues } \\
\text { estadísticas tanto para el caso donde } \mathrm{N} \\
\text { es fijo como para el caso donde } \mathrm{N} \rightarrow \infty\end{array}$ & Z-t-tilde-bar $=-6.8011$ & 0.000 \\
\hline
\end{tabular}

Fuente: Elaboración propia, con base en la revisión hecha en StataCorp (s.f.). 
Ignacio Ruelas Ávila, mexicano, es economista por la Universidad Autónoma de Aguascalientes (UAA) y maestro en Políticas Públicas por la Universidad de Chile. Fue director de Presupuesto del Gobierno de Jalisco, asesor legislativo en el Congreso Nacional de Chile y asistente de investigación, consultor y funcionario en organismos internacionales como la cepal y CREFal. Actualmente es asistente de investigación en el Centro de Investigación y Docencia Económicas (CIDE, Región Centro), docente en la UAA y asesor técnico de la Secretaría de Hacienda de la Argentina para la elaboración de una propuesta de regla fiscal (proyecto conjunto con el BID).

Alain Dimitrius Izquierdo Reyes, mexicano, es economista de la Universidad de Guadalajara (UDG), maestro en Políticas Públicas por la Universidad de Chile y candidato a doctor en Estudios Fiscales por la UDG. Se ha desempeñado en diversos cargos en materia de hacendaria y financiera en el ámbito federal, estatal, municipal y en el Congreso del Estado de Jalisco. En la academia imparte clases en posgrados y licenciatura en temas de economía y finanzas públicas, actualmente es jefe de la Tesorería del Consejo de la Judicatura del Estado de Jalisco. 